\title{
Redes férreas y patrimonio industrial en la configuración urbano-territorial de Pereira: ciudad intermedia del Paisaje Cultural Cafetero*
}

Railway Networks and Industrial Heritage in the Urban-Territorial Configuration of Pereira:

Intermediate City of the Coffee Cultural Landscape

Ferrovias e patrimônio industrial na configuração urbano-territorial de Pereira: cidade media na paisagem cultural cafeteira

Tatiana Rivera Pabón ${ }^{\star \star}$

Recibido: 30 de septiembre del 2019

Aprobado: 1 de junio del 2020

https://doi.org/10.12804/revistas.urosario.edu.co/territorios/a.8319

Para citar este artículo:

Rivera Pabón, T. (2021). Redes férreas y patrimonio industrial en la configuración urbano-territorial de Pereira: ciudad intermedia del Paisaje Cultural Cafetero. Territorios, (44), 239-269. https://doi. org/10.12804/revistas.urosario.edu.co/territorios/a.8319

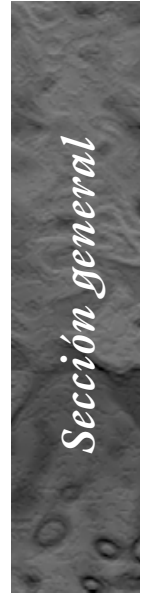

* Este trabajo hace parte de la tesis doctoral en curso "De la fragmentación a la conectividad del paisaje cafetero: una mirada sistémica al Área Metropolitana Centro Occidente y su patrimonio industrial y ferroviario", dirigida por la Dra. Vera Tângari. Este es ganador del Premio Estímulos 2017 de la Secretaría de Cultura de Pereira, en la modalidad beca de investigación en Patrimonio Cultural.

** Universidade Federal do Rio de Janeiro, Brasil, PROARQ/FAU/ UFRJ. Correo electrónico: tatianariverap@gmail. com ORCID: https://orcid. org/0000-0002-95605111 
Palabras clave

Café; configuración territorial; ferrocarril; memoria; paisaje; patrimonio industrial; sistema espacial.

Keywords

Railway; coffee;

landscape; industrial heritage; spatial system; territorial configuration; memory.

Palavras-chave

Ferrovia; café; paisagem; patrimônio industrial; sistema espacial; configuração territorial; memória.

\section{territarias 44}

\section{RESUMEN}

Este artículo propone la valoración de los doce conjuntos férreos e industriales vinculados a la producción de café en la ciudad intermedia de Pereira, Colombia, como elementos constitutivos de una tipología de patrimonio industrial agroproductivo, hasta ahora inexplorada en la declaratoria Unesco del Paisaje Cultural Cafetero (2011). Se plantea la resignificación de estos bienes culturales dentro del contexto del territorio agroproductivo, valorándolos como elementos que consolidaron el papel de la ciudad como mediadora de flujos de bienes y personas entre territorios rurales y urbanos mientras el ferrocarril se mantuvo en funcionamiento (1921-1972). A partir de la consulta de archivos históricos, entrevistas con actores locales, levantamientos urbanos y arquitectónicos, se teje una narrativa territorial y arquitectónica que, recorriendo las antiguas ferrovías desde las áreas de producción rurales hasta las de industrialización urbana, identifica los espacios, actores y temporalidades del proceso productivo cafetero local. Se destaca el potencial de esta nueva lectura histórica del territorio para valorar las configuraciones espaciales propias del proceso de modernización de la región, entender las dinámicas campo-ciudad y fortalecer la memoria social de los espacios industriales cafeteros.

\section{ABSTRACT}

This article proposes the valorization of twelve railway and industrial complexes related to coffee production in the intermediate city of Pereira, Colombia, as constituent elements of a typology of agro-productive industrial heritage, till now unexplored in the Unesco declaration of the Coffee Cultural Landscape (2011). The resignification of these cultural assets is proposed in the context of the agro-productive territory, valuing them as elements that consolidated the role of the city as mediator of flows of goods and persons between rural and urban areas, while the railway was in operation (1921-1972). Based in analysis of historical archives, interviews with local actors, urban and architectural surveys, a territorial and architectural narrative is woven along the railway, identifying spaces, actors and temporalities of the local coffee production process, from rural production areas to industrialized urban regions. We highlight the potential of this new historical reading of the territory for valuing the spatial configurations of the modernization process of the region, for understanding the urban-rural dynamics and for strengthening the social memory of the industrial coffee spaces.

\section{RESUMO}

Este artigo propõe a valorização dos doze conjuntos férreos e industriais vinculados à produção de café na cidade intermediária de Pereira, na Colômbia, como elementos constituintes de uma tipologia de patrimônio industrial agroprodutivo, até então não explorada no tombamento da Unesco da Paisagem Cultural Cafeeira (2011). Se objetiva a ressignificação destes bens culturais dentro do contexto de território agroprodutivo, valorizando-os como elementos que consolidaram o papel da cidade como mediadora de fluxos de bens e pessoas entre territórios rurais e urbanos, durante o período de funcionamento da ferrovia (1921-1972). A partir da consulta de arquivos históricos, entrevistas com a população local, levantamentos urbanos e arquitetônicos, tece-se uma narrativa territorial e arquitetônica, que recorrendo as antigas ferrovias desde as 
áreas de produção rural até as de industrialização urbana, identifica os espaços, a população, e temporalidade do processo produtivo cafeteiro local. Destaca-se o potencial desta nova leitura histórica do território para valorizar as configurações espaciais próprias do processo de modernização da região, entender as dinâmicas entre campo e cidade e para fortalecer a memória social dos espaços industriais cafeeiros.

\section{Introducción}

Localizada en un enclave geográfico estratégico de la vertiente occidental de la cordillera central colombiana y entre los tres principales polos de desarrollo económico del país -Bogotá, Medellín, Cali- (figura 1), la ciudad de Pereira fue, durante las décadas de 1930 a 1960, una de las mayores productoras de café en el país (Palacios, 1983) y, la de mayor concentración de población rural en la región del Viejo Caldas ${ }^{1}$ (DANE, 1951, 1964). $\mathrm{Su}$ actividad cafetera es un claro legado de la colonización antioqueña que, con su avance hacia los latifundios caucanos, amplió su frontera agrícola hacia esta zona a mediados del siglo XIX. Pero a diferencia de sus vecinas Armenia y Manizales, sus condiciones topográficas de pendiente leve y su proximidad al entonces navegable río Cauca, hicieron de Pereira un "vértice geográfico de las vías interiores" (García, 1978), lo que promovió y facilitó el trazado de tres líneas férreas en su jurisdicción que conectaron regiones productoras, centros comercializadores y puertos cafeteros: la línea férrea de Caldas, del Quindío y del Pacífico. De este modo, se construyeron entre 1917 y 1931 en su área urbana y rural una docena de estaciones férreas, lo cual constituye un caso destacado en el país. ${ }^{2}$

La implantación de un modelo de estaciones múltiples, alrededor de las cuales se consolidarían conjuntos ferroviarios e industriales que respondían al proceso de modernización de la agroindustria cafetera local, acabó generando un gran número de centros poblados rurales $\mathrm{y}$, definiendo nuevas centralidades urbanas. Es así como aún hoy en día con cerca de 470000 , habitantes el territorio pereirano tiene un carácter predominantemente rural $-95 \%$ de su extensión-, limitándose el área urbana al $5 \%$. Sin embargo, a pesar de la relevancia de estos conjuntos en la configuración actual de la ciudad y en la historia de la Pereira moderna, han sido abandonados, en gran parte destruidos o, absolutamente descaracterizados desde la desactivación de los ferrocarriles en la década de 1970. En la actualidad, aunque subsisten la mayoría de edificaciones e incluso algunos tramos de rieles, su conexión es ininteligible y su acceso dificultoso, pues se encuentran aislados de las vías carreteables, dispersos sobre las superpuestas vías rurales o, han sido absorbidos por tejidos urbanos periféricos conformados por población en condiciones
${ }^{1}$ El topónimo "Viejo Caldas" hace referencia al antiguo departamento colombiano de Caldas, erigido por medio de la Ley 17 de 1905 y desintegrado en 1966, cuando se segregó en tres nuevos departamentos: Caldas, Risaralda y Quindio. En términos geográficos, se ubica en los Andes septentrionales, comprendiendo zonas de las cordilleras Central y Occidental, al igual que áreas de los valles interandinos de los ríos Cauca y Magdalena (Rivera, Sánchez \& Cristancho, 2019).

${ }^{2}$ De acuerdo con la lista de bienes declarados como Bienes de Interés Cultural de ámbito nacional del Ministerio de Cultura (2020), después de Cúcuta (20), Pereira ocupa el segundo lugar en cantidad de estaciones declaradas (12), seguida de Puerto Berrio (11) y Bogotá (10).

territorias 44 241 
${ }^{3}$ Frente a este problema, el Comité de Patrimonio Mundial ha recomendado al Estado colombiano "continuar con la realización del inventario de las fincas, de los inmuebles de arquitectura urbana $y$ de los edificios asociados [...]" y "[...] continuar fortaleciendo la protección de los parámetros culturales y naturales, incluidos los edificios en las áreas semiurbana y urbana del paisaje, en general" (Unesco, 2011, p. 240).

\section{territarias 44}

de extrema pobreza en donde pasan casi desapercibidos.

De modo lamentable, los instrumentos de protección del patrimonio han respondido insuficientemente a su preservación. Ni el Decreto 746 de 1996 del Gobierno Nacional que protege las estaciones de ferrocarril, ni la reciente declaratoria de la Unesco del Paisaje Cultural Cafetero (PCC) del 2011, contemplan la valoración y protección de estos espacios industriales en su conjunto y desconocen la memoria social vinculada a ellos. En el primer caso, se tutelan solo las estaciones férreas sin valorar la conformación de los conjuntos industriales a su alrededor: bodegas, talleres, viviendas de asentamiento obrero, edificaciones anexas de procesamiento y almacenamiento de café, se encuentran actualmente desprotegidos. De otra parte, frente a la declaratoria del PCC, puede afirmarse que, dado su carácter rural y su concentración en las primeras etapas del proceso de producción del café cultivo-cosecha, se han pasado inadvertidas las fases de producción industrial y todos los espacios construidos para ello, ${ }^{3}$ e incluso, se ha subestimado el papel de los operarios cafeteros urbanos - ferroviarios, escogedoras de café, braceros, metalmecánicos - en la construcción de las ciudades cafeteras modernas.

Para responder a estos vacíos, el trabajo aborda el estudio de las redes y espacios férreos e industriales insertos en el paisaje cafetero, desde el concepto de patrimonio industrial, retomando las definiciones y recomendaciones de las cartas patrimoniales de Nyzghil Tagil (2003) y Sobrino Simal y Sanz Carlos (2019), quienes consideran que:

El patrimonio industrial se compone de los restos de la cultura industrial que poseen un valor histórico, tecnológico, social, arquitectónico o científico. Estos restos consisten en edificios y maquinaria, talleres, molinos y fábricas, minas y sitios para procesar y refinar, almacenes y depósitos, lugares donde se genera, se transmite y se usa energía, medios de transporte y toda su infraestructura, así como los sitios donde se desarrollan las actividades sociales relacionadas con la industria, tales como la vivienda, el culto religioso o la educación (Comité Internacional para la Conservación del Patrimonio Industrial, TICCIH, 2003, p. 2).

Además, acoge las sugerencias de varios autores en relación a las ventajas metodológicas de construir una lectura multiescalar del paisaje a través de las líneas férreas (Silva, Manetti \& Tângari, 2013) y, concentrarse en una determinada tipología industrial (Kuhl, 1998, 2010; Therrien, 2008), para profundizar en las relaciones de los procesos productivos con la estructuración del paisaje cultural en un contexto específico - con épocas y fases de industrialización propias-.

Partiendo de estas premisas, se busca construir una mirada sistémica de la actividad agroindustrial cafetera, desde 
la materia prima hasta el producto final, analizando el proceso productivo en su integralidad, como un proceso social con espacios y actores que producen transformaciones culturales tanto en el territorio rural como en el urbano. De este modo, se espera aportar al fortalecimiento de la identidad y cultura local, íntimamente ligada a la resiliencia de las ciudades intermedias (Ciudades y Gobiernos Locales Unidos, CGLU, 2018; Sabaté \& Galindo, 2009).

Para ello, el artículo se desarrolla en tres partes: la primera, aborda la profunda relación entre el ferrocarril y el café en la configuración territorial nacional, la región del Viejo Caldas y, en particular, se concentra en los impactos de su implantación en el espacio físico y social de Pereira, identificando los sistemas espaciales configurados para cada etapa de la cadena productiva en la ciudad. En la segunda parte, se analizan estos sistemas en el ámbito urbano, para identificar y caracterizar una tipología propia de la región: el Conjunto Industrial Cafetero (CIC) ${ }^{4}$ conformado por el conjunto férreo de la estación central, las trilladoras de café y los barrios obreros de sus entornos. La tercera parte, aborda las líneas férreas en el ámbito rural y su papel en el proceso productivo cafetero a partir de una compartimentación que permite identificar, en cada una de ellas, las manifestaciones materiales del patrimonio industrial cafetero y sus tipologías arquitectónicas, morfológicas y funcionales.

\section{Ferrocarril y caficultura en la configuración territorial nacional y regional}

La introducción del cultivo del café en el país a mediados del siglo XIX y su asociación con el tendido de líneas férreas, cambió para siempre la configuración territorial colombiana: desde procesos de redistribución regional de la población, modificaciones en las funciones y jerarquías urbanas (Zambrano, 1998), hasta transformaciones en el modelo de la red vial (Pérez, 1998). Ya desde la primera década del siglo $\mathrm{XX}$, cuando era mayormente producido en grandes haciendas de climas templados de las montañas santandereanas y cundiboyacenses, e incipientemente en Antioquia, el café impulsó la expansión ferroviaria hacia puertos fluviales de los ríos Magdalena, Cauca y Zulia, en busca de las más rápidas salidas de exportación hacia el mar Caribe (figura 1, líneas férreas en rosa). De acuerdo con Pérez (1998), "hasta 1914 los ferrocarriles cafeteros disponían de 783 kilómetros de líneas que correspondían aproximadamente al $70 \%$ de las existentes en todo el territorio nacional" (p. 12).

Mientras tanto, en la Cordillera Central, tras la fundación de las ciudades del Viejo Caldas y la ampliación de la frontera agrícola cafetera, la única vía de exportación existente se reducía a un pésimo camino de montaña que iba de Manizales a Honda, puerto fluvial sobre el río Magdalena, donde el café se
${ }^{4}$ Al respecto véase Rivera (2015). 


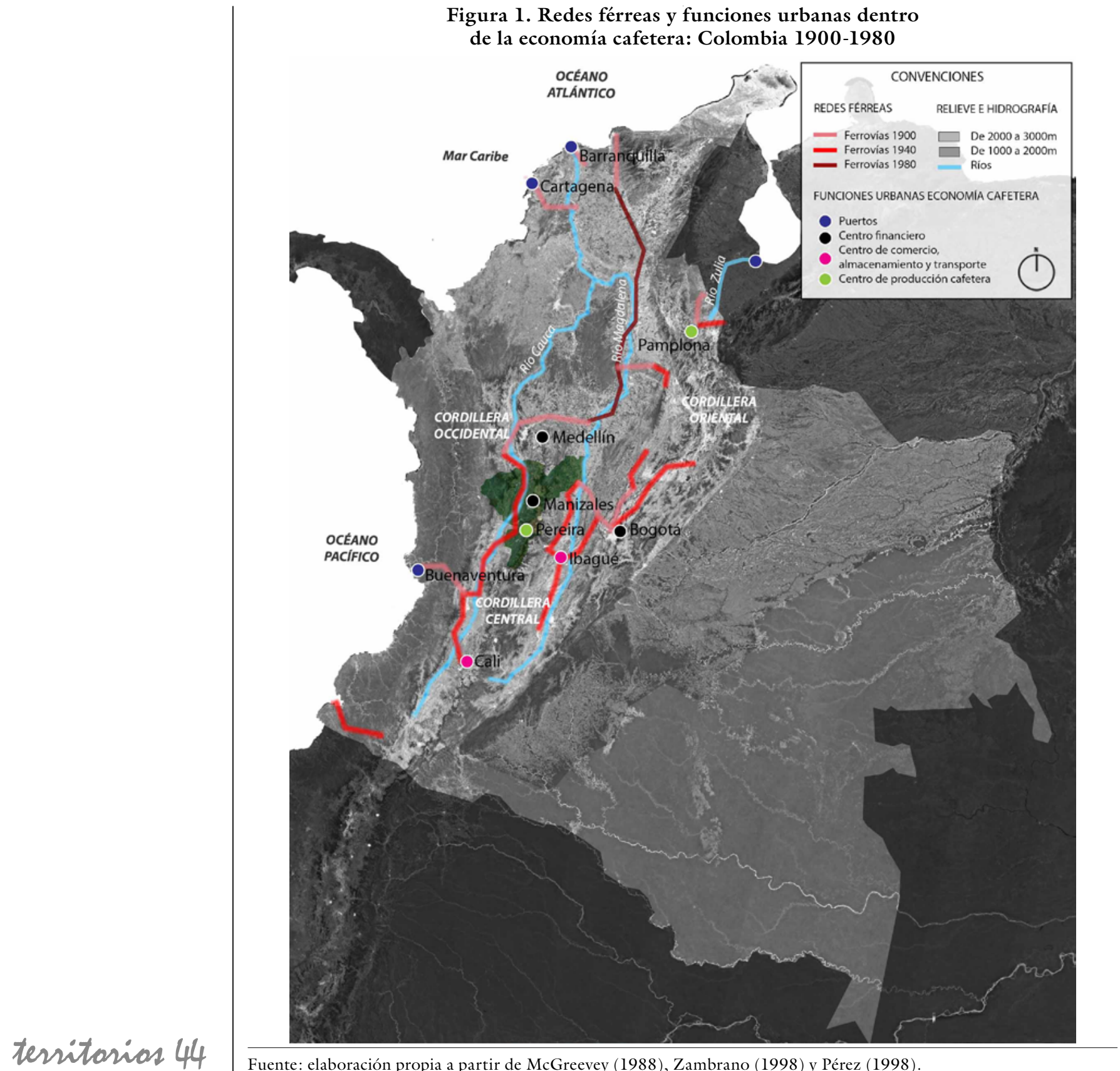


embarcaba en los vapores que lo llevaban a la Costa Atlántica. Además, existían algunos caminos de herradura que iban de Pereira y de Armenia a Cartago, donde el grano caldense se cargaba en vapores que navegaban por el río Cauca en dirección a Puerto Isaacs y, de ahí, a Cali o Yumbo en el departamento del Valle del Cauca. Por estos dos caminos, se transportaba el café en mulas y bueyes hacia el río Cauca.

Frente a esta penosa situación, la oligarquía agrocomercial manizalita comenzó la búsqueda por un nuevo canal de evacuación del café: el cable aéreo hacia el río Magdalena y el ferrocarril hacia el oeste, previendo la conexión con el ya iniciado Ferrocarril del Pacífico y la posible salida hacia el puerto marítimo de Buenaventura. Pese a la poca capacidad económica del naciente departamento de Caldas, el Estado subvencionó su ferrocarril que, conectado con el de Antioquia y el del Pacífico, conformaría una poderosa red técnica y sistema urbano interregional. Así, el Ferrocarril de Caldas logró reactivar el mercado interno y articular los núcleos de producción regional, lo cual representó la llegada de un nuevo modelo de red vial que dejó atrás a uno centrífugo que buscaba exclusivamente la conexión con el mercado externo (figura l, líneas férreas en rojo).

Este modelo de integración regional y la consecuente expansión ferroviaria, mantienen una profunda relación con la extensión de la producción de café en la Cordillera Central a partir de 1920, década en que Antioquia y Caldas sobrepasaron notablemente a Norte de Santander y Cundinamarca, asumiendo los primeros puestos en la producción de café a nivel nacional. Desde entonces, el café no solo impulsó el desplazamiento del eje poblacional de la Cordillera Oriental a la Central y, la construcción de nuevas vías de comunicación y puertos fluviales y marítimos, sino que también afianzó la industrialización a escala regional y nacional.

Para autores como Latorre (1986) y Muriel (1999), la conformación del cordón de desarrollo entre los departamentos de Antioquia, el Viejo Caldas y el Valle del Cauca, constituyó el mayor impacto de los ferrocarriles sobre el desarrollo regional y urbano. A lo largo de estos ejes viales, comenzaron a destacarse ciudades intermedias de la vertiente cordillerana cercanas al Valle del Cauca, como Manizales, Armenia y Pereira, que competían por el control comercial de la producción cafetera de sus zonas aledañas, aventajándose de sus condiciones de accesibilidad y conexión con los sistemas de transporte. Así, con la llegada del Ferrocarril de Caldas, Pereira y Armenia tomaron gran importancia no solo como productores, sino como centros comercializadores de la región centro y suroriental del departamento (figura 2).

A pesar de la centralización administrativa que privilegió por décadas a Manizales, la conexión férrea ayudó a consolidar las oligarquías comerciales de cada una de estas ciudades, que reinvirtieron los excedentes cafeteros en tres 
Figura 2. Redes férreas, cables aéreos y funciones urbanas en la economía cafetera: Viejo Caldas 1920-1972

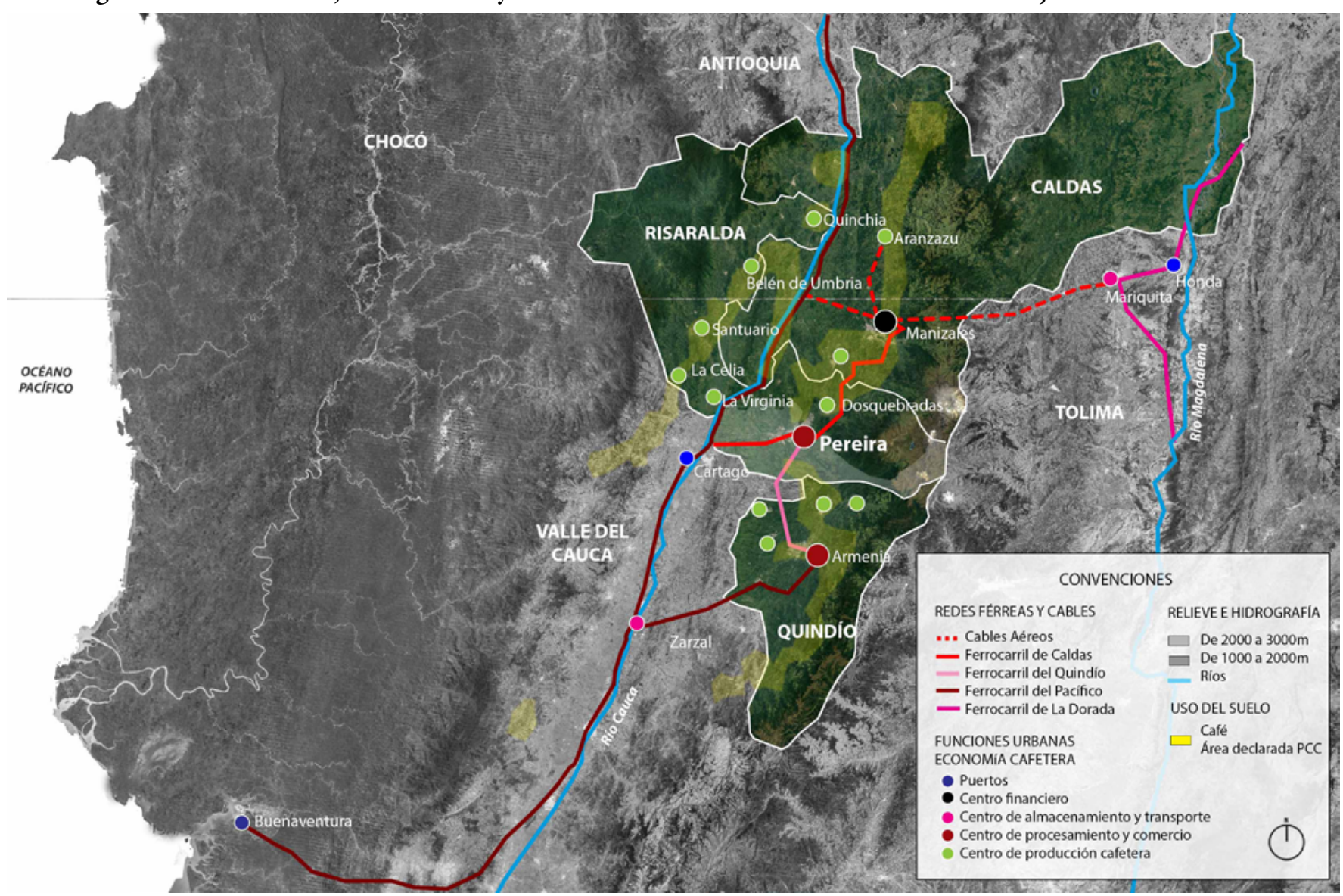

Fuente: elaboración propia a partir de Zambrano (1998), García (1978) y Mincultura (2011).

territarios 44 246 actividades principales: la creación de industrias manufactureras, la mejora y ampliación de sus cultivos cafeteros y, la construcción de infraestructura urbana. Por tanto, las obras de ingeniería, urbanismo y arquitectura que se llevaron a cabo en este periodo, buscaron modernizar el proceso de producción del café y las redes técnicas asociadas, lo cual configuró un paisaje cafetero urbano y rural moderno, estructurado a través del ferrocarril.

Este paisaje es entendido aquí no solo como un producto que se reduce al sistema físico, representado por el conjunto de formas que expresan el legado de las relaciones hombre-naturaleza en un 
momento determinado (Santos, 1996), sino también como resultado de los equilibrios particulares entre medios, intereses, representaciones e ideas de diversos grupos sociales (Capel, 2011). En esa medida, su configuración física está definida por los trazados férreos, la localización de las estaciones y, la implantación de enclaves industriales; y dependerá en gran parte del papel de cada municipio en el proceso productivo y de los impulsores de la obra. Pero además, la innovación técnica en el beneficio del café, traería la modernización del mercado laboral y la renovación de la estructura social. Y es con estas transformaciones que se responde a la nueva función de intermediación de estas ciudades entre espacios locales/regionales/ nacionales, e incluso, globales (Bellet \& Llop, 2004).

\section{El esquema de estaciones múltiples y su funcionalidad dentro del sistema espacial cafetero de Pereira}

Si bien para la segunda mitad del siglo XIX el debate sobre construir una estación central o múltiple (más de una estación en una ciudad) adquirió importancia entre los urbanistas europeos, ${ }^{5}$ contrario a las tendencias de la época en donde se procuraba elegir solo una de las dos opciones, en Pereira se ejecutaron ambas. De esta manera, en contraste con Manizales y Armenia - que construyeron una única y lujosa estación urbana-, en Pereira se optó por una solución más práctica y económica para responder a las demandas de funcionamiento interno y externo del ferrocarril: se edificó una estación intermedia más austera, pero de gran tamaño y características formales únicas, junto a un conjunto de pequeñas estaciones y paraderos ubicados en las áreas rurales de mayor producción y concentración de población.

Este esquema de "estaciones múltiples", que precisa de menor distanciamiento entre estaciones, resultó en un gran número y variedad funcional de estas. La cual es una particularidad de algunos espacios rurales productivos latinoamericanos, en que el ferrocarril sirve a los intereses de propietarios de tierras para maximizar la capacidad productiva y reducir los costes de almacenamiento y transporte. Son muy comunes en Brasil y Argentina, por ejemplo, los casos de haciendas que construyen apartaderos para su servicio, o de bodegas que se instalan buscando las líneas férreas (Capel, 2011).

Es así como a lo largo de los $101 \mathrm{~km}$ de líneas férreas de la ciudad se implantaron trece conjuntos férreos - de los cuales subsisten doce-, pertenecientes a tres compañías: el Ferrocarril de Caldas (7), del Quindío (5) y del Pacífico (1). De acuerdo con su escala y jerarquía funcional y morfológica interna, los edificios férreos pueden ser de pasajeros, de mercancías o mixtos; de cabecera y terminal, pasante, de entroncamiento o bifurcación. Sin embargo, esta clasificación tradicional del patrimonio ferroviario, muchas veces se
${ }^{5}$ De acuerdo con Capel (2011), Cerdá fue partidario de las estaciones centrales para Barcelona y Madrid, ya que la estación principal aseguraba la conexión con el centro de negocios, afirmaba que "de la misma manera que un solo puerto puede $y$ debe servir para todas las vias maritimas, una sola estación debe servir para todas las vias férreas, $y$ han de desaparecer por consiguiente esa diversidad de estaciones situadas en diferentes puntos con perjuicio de las administraciones respectivas como también del servicio público" (p. 34). Este modelo fue en el momento una aspiración de las ciudades germánicas y centroeuropeas y, solo después, de las italianas.

tersitarios 44 247 
queda corta para comprender su condición de sistema de soporte y estructurante del proceso de producción cafetero local, por lo que se ha ampliado al retomar la clasificación realizada por Aprile (1992) para la "arquitectura carrilera" de territorios agrícolas colombianos. A partir de ella, se proponen las siguientes tipologías para el caso de estudio: 1. El paradero de paso (de carga o pasajeros); 2. La estación pequeña de paso o bifurcación (de carga o pasajeros); 3. El complejo múltiple de paso (de carga y pasajeros); 4. La estación intermedia, terminal o de paso, de gran importancia en la red regional; 5. El conjunto urbano de estaciones terminales o de cabecera, ubicado en el centro urbano, acompañado de espacio público, trilladoras de café y barrios obreros.

Esta nueva clasificación incluye en sus criterios el papel del edificio o conjunto férreo dentro del proceso productivo, su funcionalidad dentro de la línea férrea, su configuración formal y agentes promotores. Considerando así el valor patrimonial de las redes férreas tanto en su dinámica interna, al ser su trazado una obra pública de gran escala que articula

Figura 3. Estructura ferroviaria y sistema espacial cafetero de Pereira
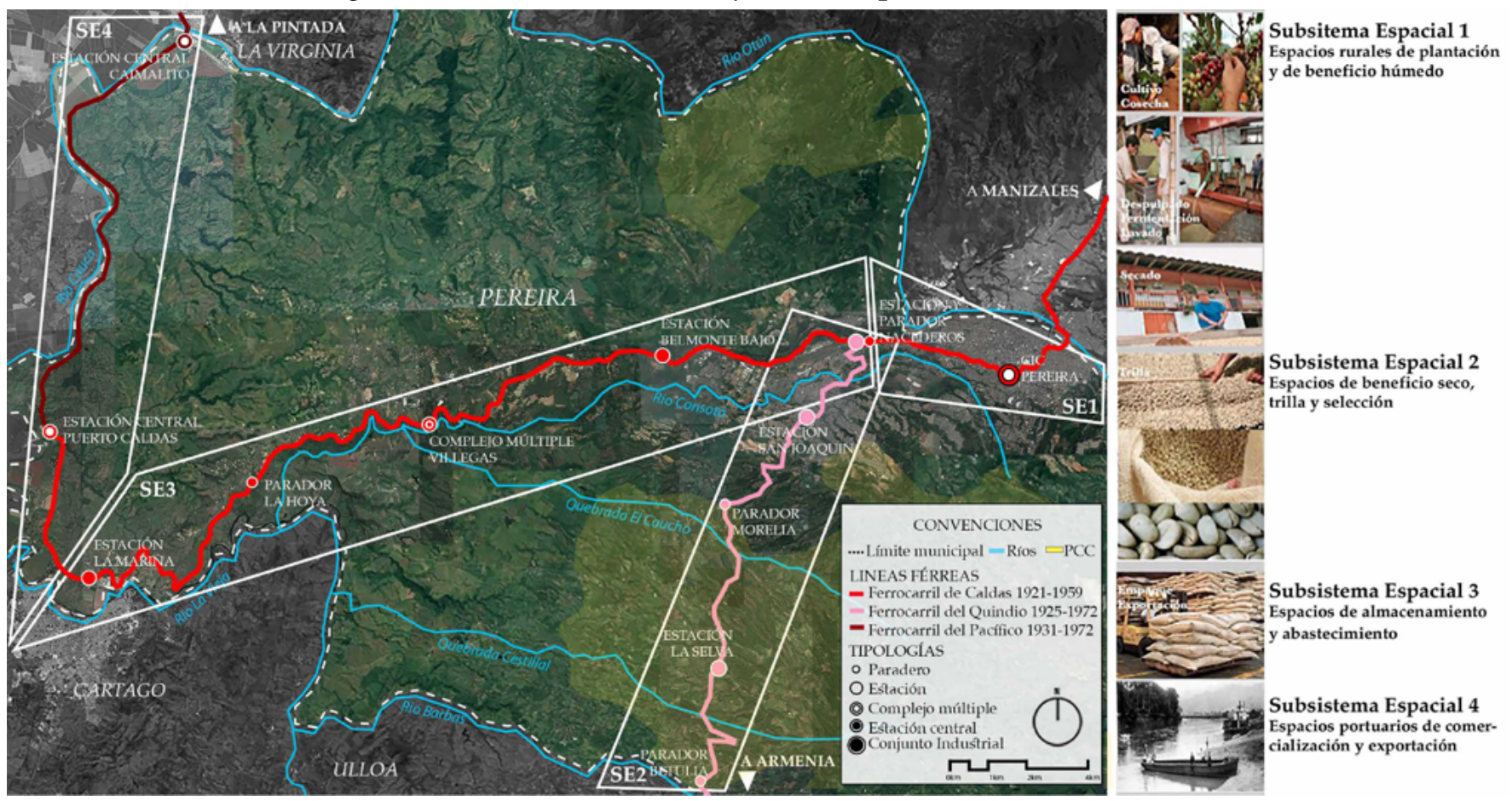

Fuente: elaboración propia (2019) 
estructuras de diversa jerarquía y obras de arte que conforman un conjunto (puentes, túneles, acueductos, alcantarillas, muros de sostenimiento), como frente a la dinámica externa, al constituir un sistema socio-técnico que define la organización de la actividad industrial de un territorio (Lalana Soto \& Santos y Ganges, 2013).

En este sentido, el patrimonio férreo de Pereira tiene valor por constituir un trazado y un conjunto de elementos interrelacionados que conectó la zona cafetera de montaña con el valle (900-1350 msnm), además de soportar y darle forma a los procesos productivos locales. No obstante, para valorarlo de esta forma se deben identificar los sistemas espaciales, definidos por la "combinação determinada de modos específicos de produção, circulação, de distribuição e de consumo de bens materiais" (Santos, 2004, p. 83), que le da al territorio una lógica funcional y un carácter propio (Argollo, 2015).

Aplicando este concepto al caso de Pereira, para el periodo de funcionamiento del tren (1921-1972), se han identificado cuatro subsistemas espaciales (SE) que corresponden a diferentes tipologías férreas e industriales:

1. Espacios rurales de plantación y de beneficio búmedo del grano, donde se concentran paraderos de carga, pasajeros y estaciones que almacenan la producción cafetera de fincas y haciendas cercanas (SEl).
2. Espacios de beneficio seco, trilla y selección en el centro urbano, donde se conforma un Conjunto Industrial Cafetero alrededor del conjunto férreo de mayor escala y complejidad (SE2).

3. Espacios de almacenamiento y abastecimiento en zonas de poca actividad cafetera cercanas al puerto, donde se instalan paradores y estaciones de pasajeros y carga (SE3).

4. Espacios portuarios de comercialización y exportación en zonas ribereñas, en las que las estaciones terminales consolidan complejos férreos de gran escala y relevancia en la red regional (SE4).

\section{El Conjunto Industrial Cafetero urbano de Pereira}

Valiéndose de las ventajas de la ubicación de Pereira en el contexto regional, la oligarquía caldense consolidó un monopolio de producción y consumo en el occidente de Caldas, aprovechando su conexión exclusiva con el Ferrocarril de Caldas y la navegación fluvial del río Cauca entre 1921 y 1923. Así, en búsqueda de un reconocimiento político en la región -en oposición al excesivo centralismo que ejerce Manizales-, se realizaron profundas transformaciones urbanas. Justamente, para demostrar su superioridad tendría que dar muestras, por un lado, de la modernización técnica que la aventajaba y que la impulsaba a la industrialización, y por otro, de la construcción de un escenario urbano burgués y de una sociedad cívica, 
- En el Contadero se estableció el primer asentamiento de colonos, era donde llegaban los arrieros a descansar $y$ hacer el conteo de mulas, de abi su nombre. De acuerdo con Zuluaga (2004), este lugar coincide con el sitio donde se erigió Cutucumanai a mediados del siglo XIX, espacio sugerido por Juan Hoyos Cabal, comisionado por el Gobierno del Canca para establecer una fonda en Cartago Viejo.

${ }^{7}$ Esto se constata en la descripción del trazado férreo realizado en la Lista de Fajas para expropiación (AGN, Tomo 323, f. 224275-276).

\section{territarios 44}

propia de las grandes ciudades y símbolo del progreso.

En este escenario, la conformación del Conjunto Industrial Cafetero de Pereira (SE2) representó la estructuración de un nuevo centro urbano con todas las características de la modernidad, su morfología rompe con los patrones urbanos tradicionales de la manzana heredada de la colonización antioqueña $(80 \times 80 \mathrm{~m})$ y se transforma aquí en una supermanzana industrial $(140 \times 500 \mathrm{~m})$, donde convergen funciones urbanas diferentes, antes dispersas: en el conjunto ferroviario, el transporte y las comunicaciones; en las trilladoras, el trabajo y la producción; y en el barrio operario, el habitar (figura 4).

La concentración de funciones en un solo espacio es resultado de un proceso de configuración territorial, en donde se establecen inicialmente los conjuntos ferroviarios como núcleos centrales originarios del conjunto industrial. En torno a ellos, se implantan posteriormente las trilladoras de café, buscando nuevas fuentes de energía y bajos costos de transporte. Con el tiempo, estas llegarían a constituir una de las principales fuerzas de mano de obra de la ciudad y, su localización impulsaría la construcción de asentamientos operarios.

\section{El conjunto férreo}

La conexión del primer centro urbano comercializador de café caldense con el puerto regional, implicó un proyecto de trazado de las líneas férreas y de implantación de una estación intermedia en la ciudad que generó profundas transformaciones en el espacio urbano, ya que marcó la orientación de su expansión, sus límites, usos y formas de crecimiento.

En primer lugar, el trazado, proyectado por el ingeniero Luis Isaza - comisionado por la Junta del Ferrocarril de Caldassobrepone la ferrovía al camino colonial que, siguiendo el curso de la quebrada Egoyá, conectaba a Cartago Nuevo con el sitio conocido como el Contadero de Egoyá, ${ }^{6}$ y de este, con Manizales. Este camino había definido hasta 1920 el borde sur de la ciudad, pero el deseo de incorporar el conjunto férreo al área urbana hizo que se ampliaran los linderos de la ciudad, estableciendo nuevos límites en el borde sur (Acuerdo 21, 1920, art.1). De esta forma, al llegar la línea férrea al área central de la ciudad - prolongación de las calles inscritas entre la Plaza Victoria y Parque el Lago-, la traza se alejó del eje natural hasta el máximo permitido por las condiciones topográficas. Desplazándose cuatro manzanas hacia el sur, la línea atraviesa grandes propiedades no urbanizadas en este costado, mientras hacia el oriente, corta la trama urbana ya edificada. ${ }^{7}$

En esta nueva área urbanizable se implantó un modesto conjunto férreo agrupado linealmente y compuesto por una estación central mediana, dos bodegas laterales y un taller (figura 5). La estación original que se estaba construyendo con motivo del arribo de la primera locomotora 
Figura 4. Conjunto Industrial Cafetero de Pereira

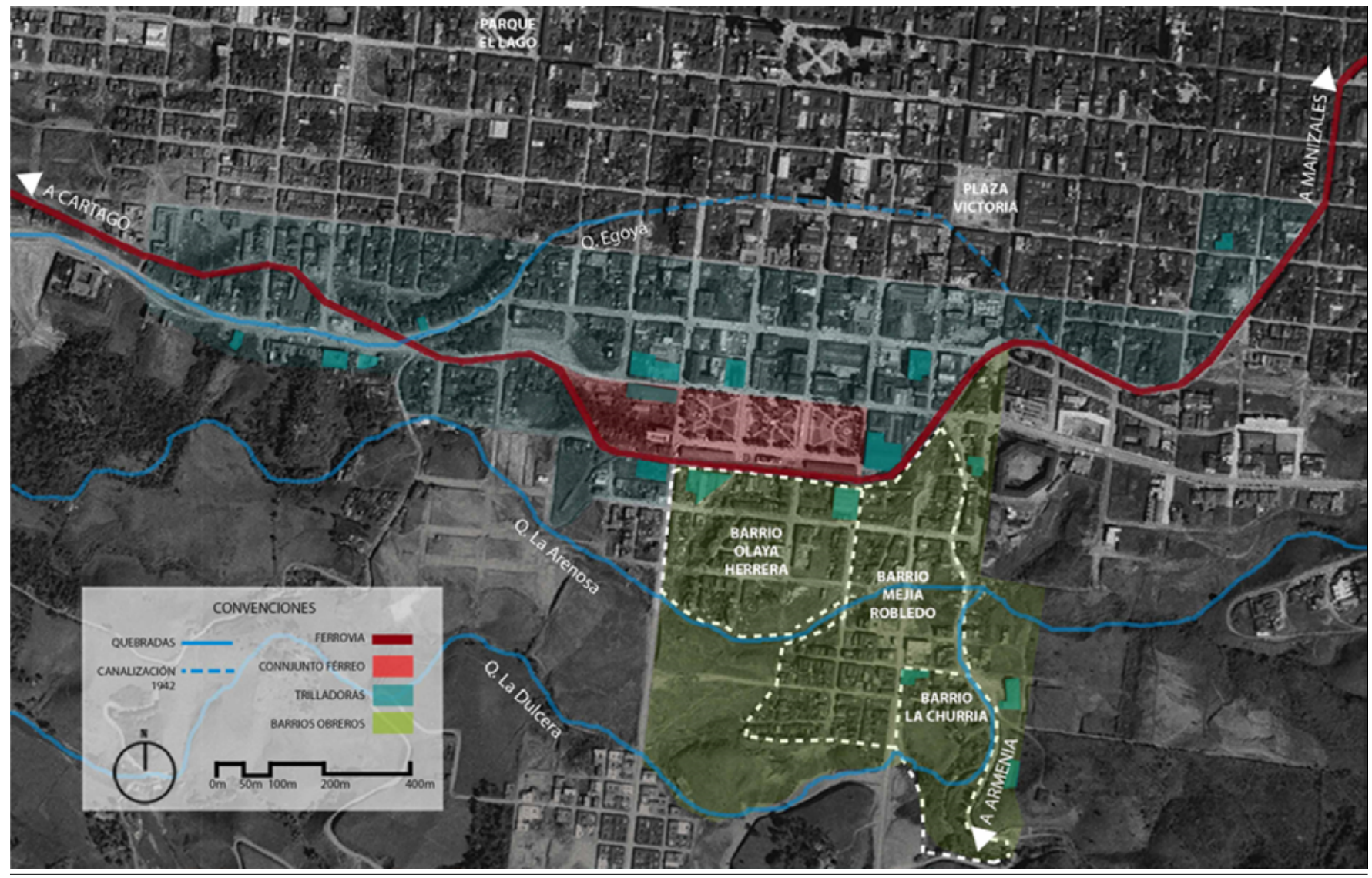

Fuente: elaboración propia a partir de fotografía aérea del Instituto Geográfico Agustín Codazzi, IGAC (1954) y Cámara de Comercio de Pereira (2013).

a Pereira, el 8 de julio de 1921, consistía básicamente en una casa de bahareque con un corredor lateral que servía de plataforma para el recibo de los trenes, de técnicas constructivas y factura similar a las estaciones rurales anteriores de la misma línea (figura 8). Sin embargo, llegada la década de 1930 se conoció un nuevo edificio de dos pisos de estilo republicano, construido en ladrillo macizo, placas de hormigón armado y con terrazas laterales de estructura metálica. Aunque es solo iniciada la década de 1940 que se introduce el repertorio Art déco que hoy conocemos, incluyendo la torre central de la que se destaca su reloj mecánico. Con estos cambios se exhibirá finalmente el éxito y la prosperidad económica en forma territarias 44 


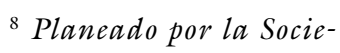
dad de Mejoras Públicas a partir del proyecto del artista manizalita Gonzalo Quintero, a imagen y semejanza de los parques europeos que la élite exportadora de café tenía como referente por sus viajes de negocios: con jardines afrancesados de trazado radial engalanados con fuentes, esculturas y coretos.

\section{territarias 44}

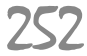

de monumento - como ya se había hecho en Manizales-, en la estación terminal cabecera de la línea.

Empero, más allá de la estación, el trazado y el conjunto férreo generaron efectos diversos sobre el espacio urbano: positivos en el sector comprendido entre la estación y el centro de la ciudad, donde se configura una plaza urbana moderna de grandes proporciones - hoy, Parque Olaya Herrera- ${ }^{8}$ conectada con el área central a través del tranvía; y negativos, al otro lado de la vía donde se concentran los usos industriales y la vivienda informal. Por tanto, la ferrovía representó la división entre una zona planificada y una zona autoconstruida, lo cual produjo una discontinuidad en el espacio urbano que dio lugar a espacios intersticiales o en situación marginal (Capel, 2011).

El entorno del conjunto férreo fue entonces el espacio donde se expulsaron los usos indeseables de la ciudad, entre ellos el industrial, que ya venía generando efectos adversos en el área central, como incendios y problemas respiratorios. Allí se instalaron modernas trilladoras de café y las primeras fábricas metal-mecánicas. A ello contribuye la prohibición - bajo pena de multa-, del Concejo Municipal por construir nuevas fábricas en el área central y en particular, establecimientos para secar mecánicamente el café:

Queda prohibida terminantemente la construcción de estufas para secar café, velerías, jabonerías, fundiciones [...] y en general todos los establecimientos que ofrezcan peligro de incendio [...] entre las carreras quinta y doce, y las calles 10 y 27 (Acuerdo 4,1924 , art.1).

Queda absolutamente prohibido el funcionamiento de estufas y guardiolas de secar café en el área de población de Pereira. Los establecimientos de la clase indicada pueden funcionar hasta tres meses después de la vigencia de este acuerdo, con el fin de que sus propietarios puedan disponer de este término para beneficiar el café que allí conservan en la actualidad, pero con la condición expresa de que aquellos solo funcionen en las horas del día (Acuerdo 33, 1926, art.1)

Esta serie de prohibiciones y el consecuente traslado de los usos industriales hacia el borde sur, actuó como un factor aglutinador de almacenes relacionados con la modernización del espacio agrario, y en esa medida, dio espacio no solo a la producción de café, sino también, aunque en menor medida, a la fabricación, comercialización y abastecimiento de maquinaria y productos agrícolas. Así pues, el conjunto férreo no solo tendría ahora una función para la comunicación y el transporte, sino también una connotación de conjunto industrial.

No obstante, estas actividades provocaron la desvalorización de los espacios “más allá de la ferrovía” y generaron un efecto barrera de la ferrovía en la ciudad, que serviría para justificar el levantamiento 
Figura 5. Conjunto férreo en el costado sur del Parque Olaya Herrera, década de $\mathbf{1 9 7 0}$

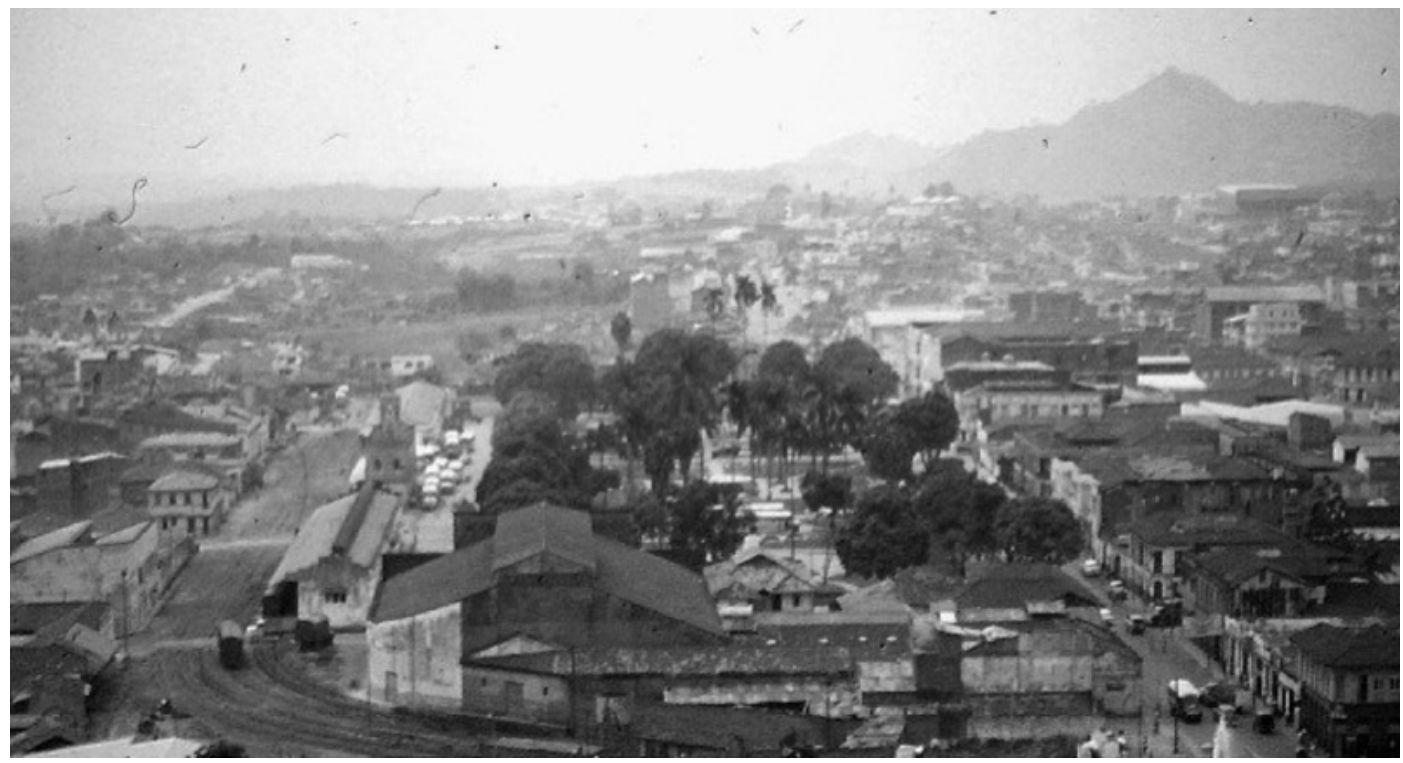

Fuente: Medina (1971).

de los rieles en 1959, a quienes la veían como un impedimento para la expansión de la ciudad formal.

\section{Las trilladoras de café}

La aparición de trilladoras mecánicas en Pereira, su localización y evolución técnica, tuvo una relación directa con el tendido de las líneas férreas y la búsqueda de nuevas fuentes de energía. Antes del ferrocarril, las trilladoras seguían un patrón de localización que envolvía áreas periféricas y rurales, cercanas a ríos y quebradas, donde grandes caídas de agua podían asegurar tanto el suministro constante del recurso, como una eventual generación de energía

hidráulica. En este periodo, se localizaban de forma dispersa en haciendas tecnificadas, cercanas a las vías de transporte que comunicaban a los centros de compra del grano con los centros de producción entre los municipios de Pereira y Santa Rosa, Armenia y La Virginia. Algunas de estas como La Julia, El Jardín y El Polo, propiedad de los primeros comerciantes y exportadores de café caldenses, beneficiaban no solo su café sino el de fincas cercanas y, además, proveían de energía eléctrica a la ciudad. ${ }^{9}$ La conexión con nuevas infraestructuras y redes técnicas les permitió acrecentar sus capitales y establecer un monopolio que controlaba el sistema comercial y de beneficio del
${ }^{9}$ Entre estos se destacan Mariano Mejia, propietario de la Hacienda Canceles; Carlos E. Pinzón, quien estableció varias trilladoras y tostadoras en la región, siendo el primero en introducir el sistema de guardiolas (Arango, 1981); y Luis Jaramillo Walker, manizaleño que sembró los primeros cafetales técnicos en la región. Su bacienda La Julia, valorada como "una de las más valiosas baciendas agricolas de la República" (Posada, 1918, p. 335), contaba con el mayor número de árboles en producción del pais y fue alli donde se estableció la primera trilladora de la ciudad en 1870. Captando la fuerza hidráulica de las fuentes hidricas de su propiedad, no solo beneficiaba su café, sino que proveía de energía a otras empresas como "a la luz eléctrica que sirve a la ciudad, a la trilladora de don José Carlos Villegas, a la fundición de Don Antonio Quintero y a la trilladora y maquinarias de la misma hacienda" (Ángel, 1983, p. 273). En este sentido, también se destaca la trilladora de la Hacienda El Polo, ubicada en el camino a Santa Rosa, cuyos propietarios

\section{$\Longrightarrow$}

\section{territarias 44}

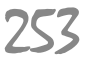


fundaron la Empresa y la Planta de Energía de la ciudad en 1914.

${ }^{10}$ Varios autores coinciden al respecto, García (1978) afirma que "el sector más voluminoso de trabajadores del café es el correspondiente a trilladoras” (p. 311); Escobar (1995, p. 71) amplía diciendo que "este sector es el que mayor fuerza de trabajo presenta, para la década de los años 30, dentro de la industria cafetera; también es el que tiene mayor diversificación y desarrollo" (p. 71). $\Upsilon$ Ramirez (2010), en trabajos más recientes reitera que "el proceso de trilla de café se concentró en los centros urbanos, en los cuales se dieron relaciones de contratación y los obreros asalariados empleados en las trilladoras representaron la mayoría de la fuerza de trabajo del sector manufacturero del pais” (p. 126).

\section{territarias 44}

grano, y por tanto, apoyar y promover la construcción del ferrocarril, las redes de electricidad y telefonía.

Tras la crisis de 1929, empresas extranjeras vieron la posibilidad de invertir en el sector cafetero (tabla 1), por lo que adquirieron y reestructuraron comercialmente las casas exportadoras nacionales con sede en Pereira, aumentando la escala de producción e introduciendo nuevas técnicas (Arango, 1981). En este segundo periodo, contemplado entre las décadas de 1920 a 1940 , las trilladoras siguieron un patrón de localización alrededor de la estación y a lo largo de la red férrea (figura 6), marcando su presencia con grandes edificios-fábrica de estilos diversos, desde aquellos coloniales y republicanos hasta modernistas, como fue el caso de la trilladora y el almacén de depósito de la Federación Nacional de Cafeteros.

Al exigir terrenos mayores, las trilladoras se constituyeron en grandes consumidoras de espacio. Lo cual se resolvió a través de alineamientos industriales a lo largo de la ferrovía, que posibilitaban la accesibilidad a los mercados, a nuevas fuentes de energía eléctrica, a terrenos amplios y baratos, así como a la proximidad de la fuerza de trabajo. En estos “distritos industriales" (Lobato, 1989), las casas exportadoras extrajeron al máximo la plusvalía del trabajo obrero con una modalidad de asalariados nunca vistos en los centros urbanos, que agruparía la mayor cantidad de obreros de la industria nacional. ${ }^{10}$
Tabla 1. Café exportado desde Pereira, 1939

\begin{tabular}{|l|l|c|}
\hline \multicolumn{1}{|c|}{ Exportadores } & \multicolumn{1}{|c|}{ Destino } & Bultos de 70 kg \\
\hline Grace \& Co. & $\begin{array}{l}\text { San Francisco } \\
\text { New York } \\
\text { New Orleans }\end{array}$ & 4941 \\
\hline $\begin{array}{l}\text { American } \\
\text { Coffee Corp }\end{array}$ & $\begin{array}{l}\text { New York } \\
\text { El Havre }\end{array}$ & 4618 \\
\hline $\begin{array}{l}\text { A. Aristizabal } \\
\text { \& Co. }\end{array}$ & $\begin{array}{l}\text { New York } \\
\text { Chicago }\end{array}$ & 2600 \\
\hline $\begin{array}{l}\text { Eduardo } \\
\text { Trujillo \& Co. }\end{array}$ & $\begin{array}{l}\text { New York } \\
\text { San Francisco }\end{array}$ & 1590 \\
\hline $\begin{array}{l}\text { Hard \& } \\
\text { Rand Inc. }\end{array}$ & $\begin{array}{l}\text { New Orleans } \\
\text { New York }\end{array}$ & 1323 \\
\hline $\begin{array}{l}\text { Rafael Jenaro } \\
\text { Mejia }\end{array}$ & $\begin{array}{l}\text { New York } \\
\text { San Francisco }\end{array}$ & 1134 \\
\hline $\begin{array}{l}\text { Stenwender } \\
\text { Stoffregen Corp }\end{array}$ & New York & 1069 \\
\hline Eliseo Lopez & New York & 520 \\
\hline $\begin{array}{l}\text { Pedro Bernal } \\
\text { Ela Cafetera } \\
\text { de Manizales }\end{array}$ & New York \\
\hline $\begin{array}{l}\text { Jesus Maria } \\
\text { Lopez \& Cia. }\end{array}$ & New York \\
\hline Tracey Brothers & New York & 509 \\
\hline Total & 5908 \\
\hline
\end{tabular}

Fuente: Revista Cafetera de Colombia (1940).

En tal sentido, la trilla de café generó nuevas dinámicas sociales urbanas, como cuentan Duque, Friede y Jaramillo (1963, p. 393): 
Figura 6. Trilladoras de café alrededor de la estación y a lo largo de la línea férrea

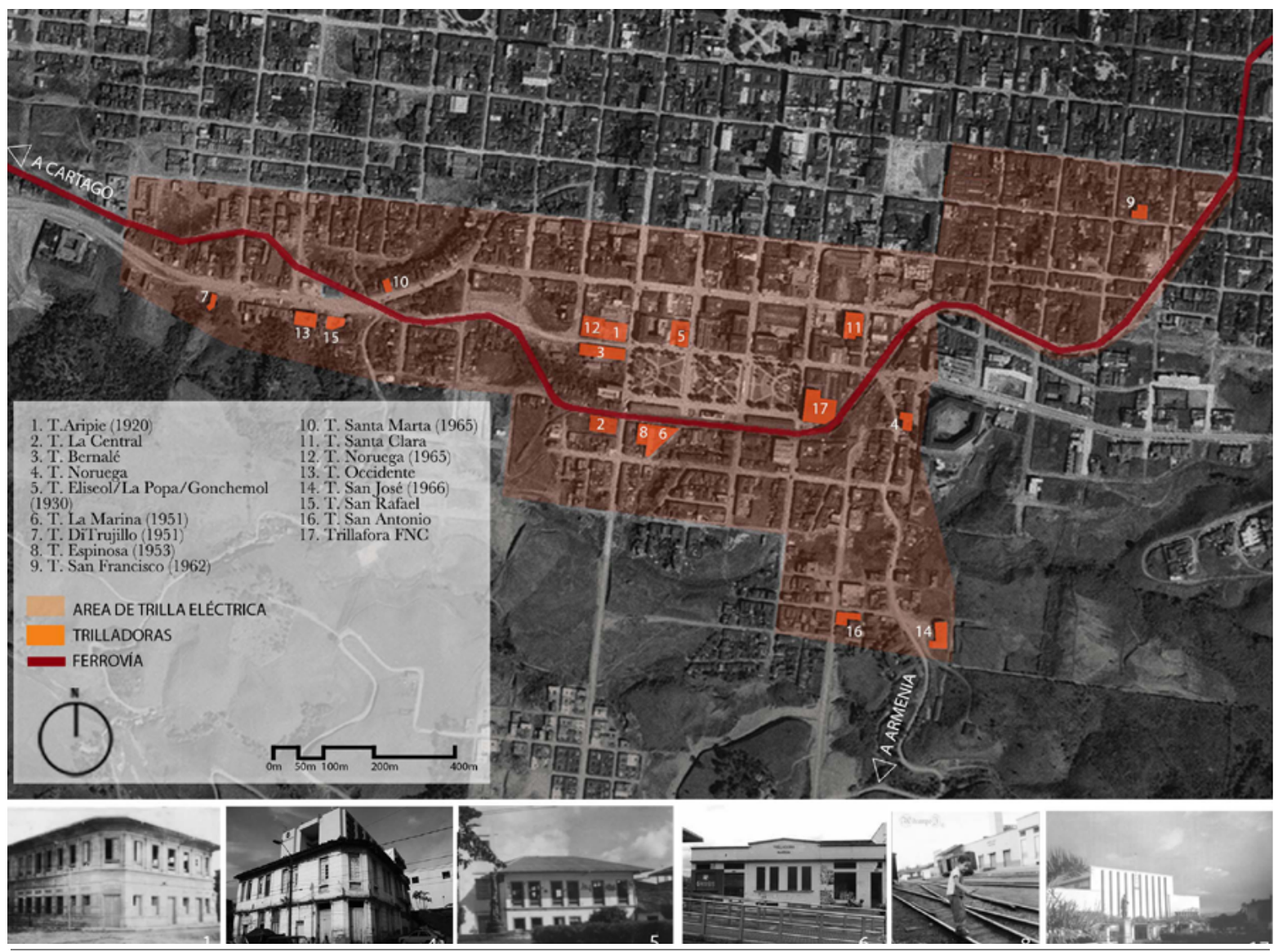

Fuente: elaboración propia a partir de aerofotografía IGAC (1954), Cámara de Comercio de Pereira (2013) y Camacho (2013).

La trilla de café era una actividad perfectamente industrial y que ocupaba centenares de obreros, sobre todo mujeres. Es significativo que en ella aparecieron por primera vez los sindicatos obreros y que también en ella se produjera la primera huelga de importancia que conoció la ciudad.
Es así como el conjunto férreo e industrial se convertiría en un nuevo centro de expresión de reivindicaciones laborales y luchas sociales de la nueva clase operaria urbana. Pero, además, la concentración espacial de los medios de producción y de la fuerza de trabajo en el CIC, trajo consigo una nueva cuestión: el problema habitacional. tersitarios 44

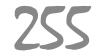


11 Estos barrios fueron blanco de las medidas punitivas de la primera ley de vivienda obvera formulada en 1918, que "prohibe el arrendamiento de casas, apartamentos, cuartos, etc, sin condiciones higiénicas minimas, bajo pena de multas" (Ceballos, 2008, p. 25), pues además de que alli proliferaban los inquilinatos, ocupaban zonas de riesgo y su construcción e infraestructuraseran muy deficientes.

12 Según el Acuerdo $n .^{\circ} 3$ de 1942, art.1, del Consejo Municipal de Pereira, por iniciativa de los propietarios de terrenos vecinos a la estación férrea-Jesús Salazar, Julio Puerta y Rubén Sanin-, se firmó un contrato con el municipio, donde se comprometian a localizar y construir calles $y$ carreras, perfiles de vías $y$ alcantarillado para los predios de su propiedad en el entonces barrio La Estación. El municipio se comprometió a pagar a cambio, el valor de cada cuadra de alcantarillado y se dio un plazo de 5 años para entregar los trabajos.

${ }_{13}$ Mientras los caucanos proponian el ascenso por la via Quebrada Grande

territarias 44

\section{Los barrios obreros}

Aunque el trazado del ferrocarril se impuso como una forma de estimular el uso industrial y controlar el residencial en el borde sur, la demanda de vivienda por parte de la nueva clase operaria no pudo esperar y rápidamente traspasó los límites. Así, para sorpresa de muchos, la ferrovía también estimuló la ocupación de tierras periféricas y la urbanización "más allá" de la línea férrea, fuera del área urbana. A pesar de las dificultades relacionadas con la topografía, se dio comienzo a la urbanización marginal en el área comprendida entre las quebradas La Arenosa y La Dulcera, cuyo margen definió el nuevo límite natural para la expansión (figura 4). Aunque en un periodo de políticas de vivienda higienista, donde los temas habitacionales eran tratados como problemas de salubridad, estas nuevas ocupaciones entraron en la mira de las autoridades dadas sus condiciones precarias.

Así pues, al mismo tiempo que se construía el Parque Olaya Herrera - como la cara agradable de entrada a la ciudad por la vía férrea-, del otro lado crecía rápidamente la periferia marginal. En un primer momento, aprovechando la construcción de la vía Pereira-Armenia surgió el asentamiento informal que daría origen al barrio Mejía Robledo (1930) y, años más tarde, ocupando el curso de la quebrada La Dulcera, nacería el barrio La Churria o Travesuras (1934). ${ }^{11}$
Más adelante, ya acercándose al área urbana y conformando el frente sur del conjunto férreo, se creó el barrio Olaya Herrera (1945), fruto del emprendimiento particular de propietarios de tierras que actuaban como urbanizadores. ${ }^{12}$ En él conviven hasta hoy en día fábricas, talleres y viviendas (figura 7 ).

\section{Trayectos férreos rurales}

\section{Ferrocarril de Caldas: de Puerto Caldas $(\mathrm{km} \mathrm{0)}$ a Pereira $(\mathrm{km} \mathrm{40)}$}

La línea férrea que buscaba la comunicación de la aislada y elevada ciudad de Manizales (2200 msnm), capital del departamento de Caldas con el Océano Pacífico, conectó en su primera fase a Pereira con la salida más conveniente de exportación para el departamento en ese momento: Puerto Caldas. El trazado definido, resultado de una larga disputa entre caucanos y caldenses, ${ }^{13}$ "partía del río Cauca hacia el oriente, pasando un poco al norte de Cartago y tomando la ladera norte del río Consota, trepando por ella hasta la planicie ondulada donde se asienta Pereira" (Archivo General de la Nación, AGN, Tomo 323, f. 66). De ese modo, ascendió de los 900 hasta los $1350 \mathrm{msnm}$, atravesando tres relieves y climas diversos: un paisaje de valle con planicies aluviales y terrazas disectadas de clima cálido-seco en la zona ribereña, uno de montaña con vertientes en el ascenso desde La Hoya a Villegas y, uno de piedemonte con clima 
Figura 7. Estación del ferrocarril desde el Barrio Olaya Herrera

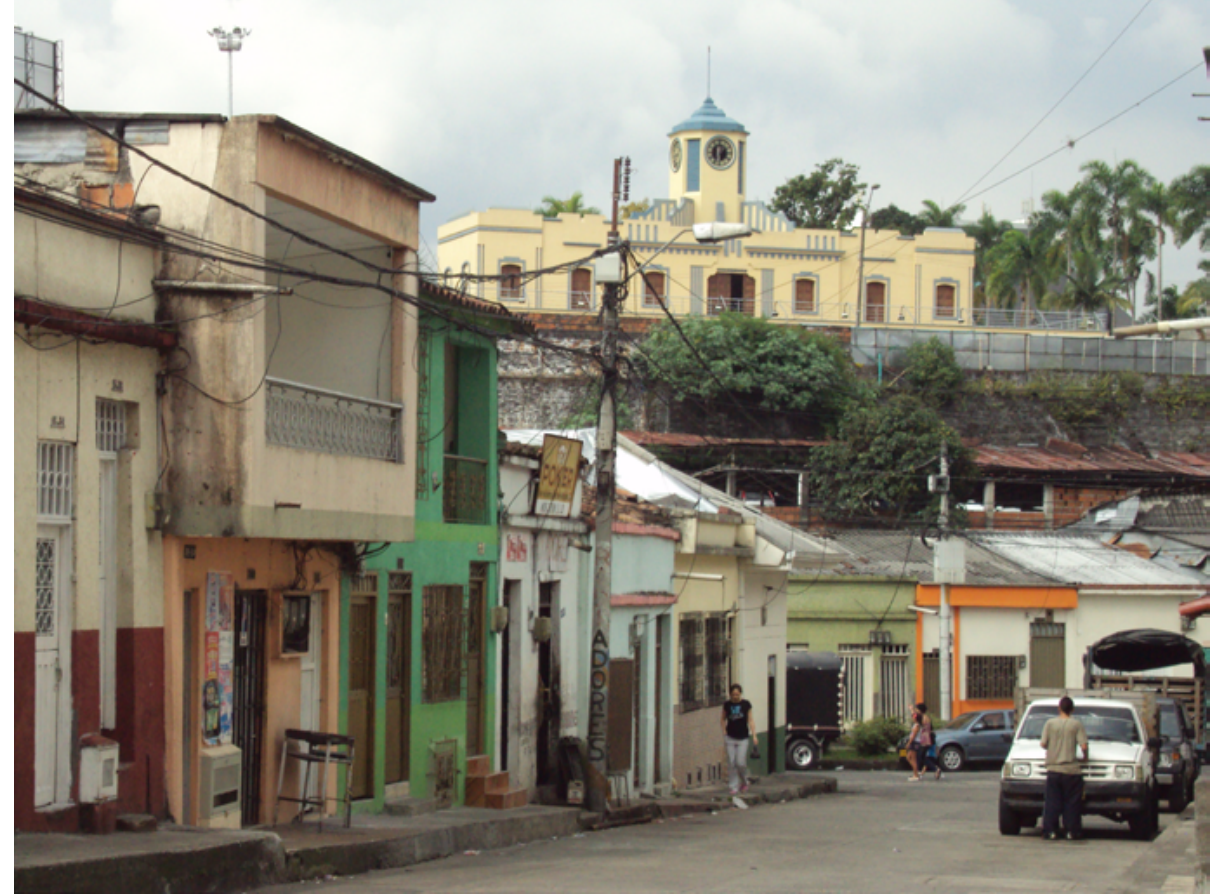

Fuente: elaboración propia (2019).

templado y húmedo en el tramo del área urbana central, hasta llegar al Conjunto Industrial Cafetero (figura 3).

Fue construida entre 1915 y 1921 por la Empresa Ferrocarril de Caldas, propiedad del departamento, de acuerdo con la dirección de ingenieros locales y asesoría estadounidense en algunos tramos. ${ }^{14} \mathrm{~A}$ lo largo de sus $40 \mathrm{~km}$ se implantaron en las propiedades de mayor tamaño (superiores a 5 ha), una estación terminal, cuatro estaciones de paso y dos paraderos, con una distancia de 4 a $5 \mathrm{~km}$ entre ellas, a saber: Estación Puerto Caldas, Estación

La Marina, Parador La Hoya, Estación Villegas, Estación Belmonte, Paradero Nacederos y Estación Pereira. A ellas, se suman bodegas, embarcaderos, campamentos de obreros, dos túneles, un puente metálico, muros de contención, alcantarillas, tanques, entre otras obras de arte (figura 8, edificios desaparecidos en rojo).

A pesar de que en las estaciones medianas como la de Pereira, se introducen nuevos estilos y técnicas constructivas, esta línea constituye un ejemplo de conservación de la arquitectura vernácula en las estaciones rurales menores. Allí,
(1915), que seguía el curso del rio Otún y atravesaba grandes propiedades; los caldenses defendian que la mejor ruta era la vía Consota, que además de tener una menor concentración de la tierra, garantizaba mayor facilidad y agilidad en la ejecución de las obras, y más potencialidades comerciales $y$ de conexión con el sistema férreo nacional. (AGN, Tomo 323, f. 156-240).

${ }^{14}$ Entre los locales están los ingenieros Jorge Escobar, Carlos de la Cuesta y Eleuterio Serna. También participaron los estadounidenses AF Morris y John Lee, en algunos tramos de mayor dificultad topográfica y técnica, como La Hoya-Villegas.

tersitarios 44

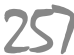


Figura 8. Trayecto Estación Central Pereira-Puerto Caldas

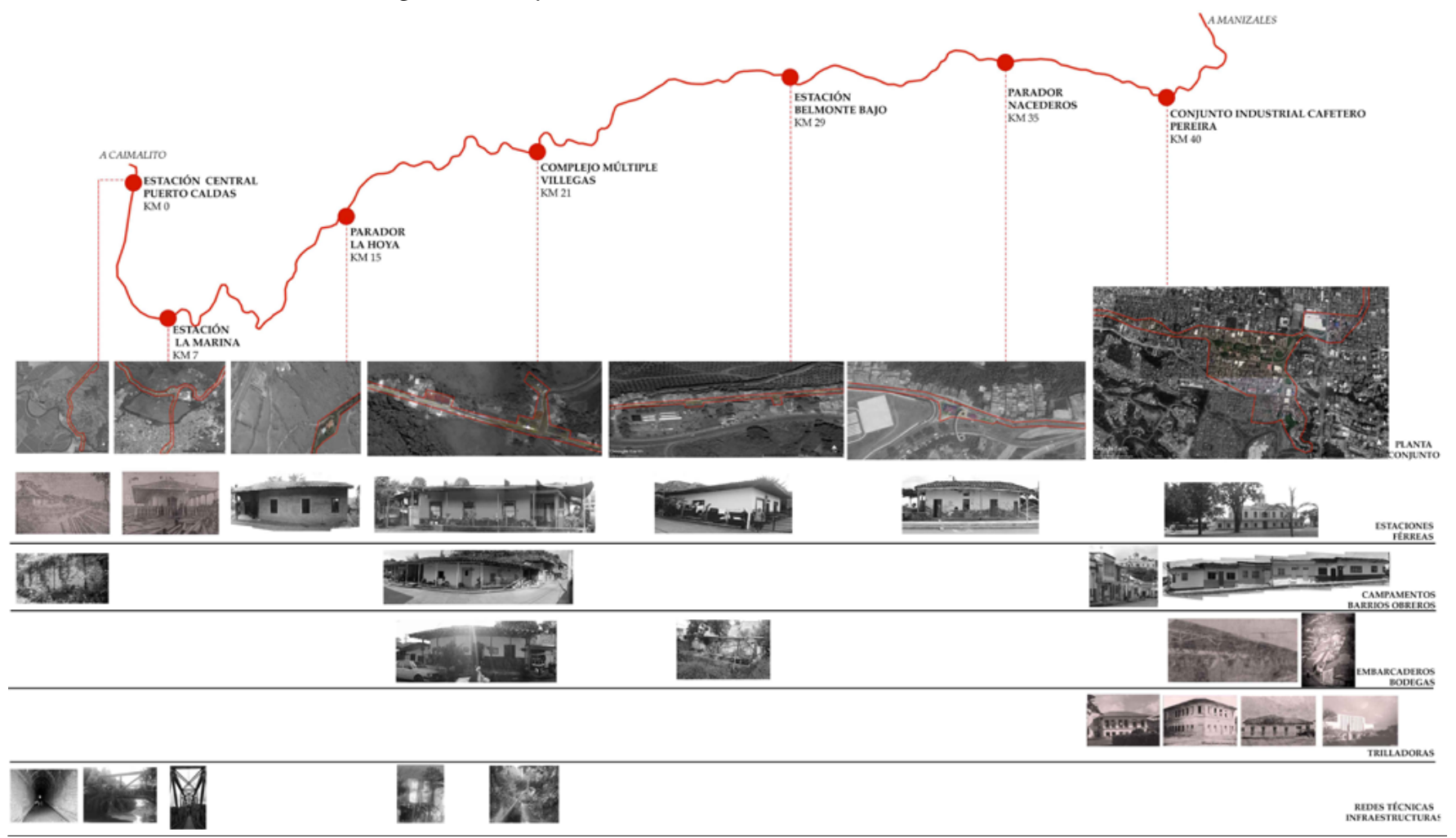

Fuente: elaboración propia con base en aerofotografías actuales Google Earth (2019), García (1938, 1970) y “Microfilmado” (2019).

territarios 44 258 a la planta tipo de estación en forma de barra alargada, se le sobreponen las tradiciones constructivas de la colonización antioqueña: muros de bahareque o adobe, corredores perimetrales, cielorrasos, zócalos de madera y cubierta en teja de barro. Por tanto, a pesar de que no tienen un valor estético individual destacado, sí lo tienen en su conjunto, al ser representativo de la edilicia regional de la época. Pero fuera de eso, tiene una relación funcional con los procesos productivos territoriales y, en especial, con la cadena productiva cafetera.

El primer tramo, comprendido entre la estación terminal Puerto Caldas y La Marina - de conexión con la línea del Pacífico-, abarca el subsistema de espacios portuarios de comercialización y exportación (SE4). Estos fueron construidos a orillas del río Cauca, entre Cartago y La Virginia, en una zona de grandes haciendas ganaderas y azucareras. Allí se fundó en 1917 la población de Puerto Caldas, 
puerto intermodal de gran actividad por donde se movilizaron unos 800000 sacos de café durante el periodo de auge del transporte fluvial a vapor (1917-1923) (Ramírez, 2016). Como estación central de gran importancia para la red regional, constituyó uno de los conjuntos férreos de mayor complejidad, compuesto por "los edificios para las estaciones que están cubiertas con teja metálica y tienen muros de adobe. Hay además tres bodegas de carga, una casa para los ingenieros, un pequeño hotel y un almacén" ("Microfilmado", 1919, p. 119), además de "una fragua y un tejar" (AGN, Tomo 323, f. 111), talleres y campamentos de trabajadores del ferrocarril.

No obstante, tras la llegada del Ferrocarril del Pacífico a Cartago en 1924, que tenía conexión férrea directa hasta Buenaventura, el puerto fluvial comenzó su decadencia. Hoy sus ruinas están totalmente aisladas y desconectadas de la red vial, por lo que es difícil identificar su ubicación y la de los edificios que lo componían. Fuera de esto, los entornos de la línea cercanos a la estación La Marina, atrajeron actividades industriales y fueron ocupados, lo cual dio lugar a un denso asentamiento informal periférico que, a pesar de hacer parte del municipio de Pereira, tiene como centralidad la ciudad de Cartago.

En los tramos restantes, entre La Marina y Estación Pereira, se localizan los espacios de almacenamiento $y$ abastecimiento (SE3) que sirvieron, por un lado, como lugar de acopio de la producción local, y por otro, como escala de abastecimiento y mantenimiento para el buen funcionamiento del tren. Aquí, la ferrovía atraviesa haciendas ganaderas, ingenios, trapiches de gran extensión, y pocos cafetales de medianas propiedades, ya que, al ser un territorio históricamente limítrofe entre frentes de colonización, está marcado por tradiciones agrarias y formas de tenencia de la tierra diferentes: latifundista azucarera de un lado y, minifundista cafetera del otro. Por esta razón, en las bodegas y embarcaderos de estas estaciones y paraderos se almacenaban cargas de caña, azúcar, ganado y café, para ser transportadas hacia el Valle, Antioquia y el Caribe, como afirman vecinos de los entornos ferroviarios: "El café se sacaba para trillar en el Valle [...] pero lo que más llegaba aquí era ganado (Francisco Sánchez, comunicación personal, 2017).$^{15}$

Aquí llegaba el tren de pasajeros y llegaba el tren con ganado, de Antioquia, de la Costa [...] La hacienda cafetera de por aquí era La Camelia, del doctor Jaime Botero. El resto eran cañeras y ganaderas: San Antonio, Santa Marta, Monserrate, San Cayetano, El Tigre, Quimbayita [...] Llevaban la caña panelera en camionetas para los trapiches, la sacaban en mulas hasta aquí (Carlos Vélez, comunicación personal, 2017). ${ }^{16}$

Entre las estaciones, cabe destacar el papel de la Estación Villegas como complejo múltiple de carga y pasajeros, donde
${ }^{15}$ Francisco José Sánchez. Habitante del sector Estación Villegas desde el 1970.

16 Carlos Arturo Vélez Carvajal. Hijo del jefe de bodegas de la Estación de Armenia, habitante de Belmonte Bajo desde 1954.

territarias 44

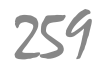


${ }^{17}$ Alirio Grajales. Habitante del sector de Estación Villegas desde 1958.

18 Sobre las ventajas del trazado y su vocación cafetera, el ingeniero Latorre, administrador de la línea, afirmaba en 1928 que la región era "de una feracidad y riqueza extraordinarias $y$ está dedicada a la agricultura y la ganadería, con especialidad al cultivo de la caña de azúcar y el café, productos estos que son de excelente calidad, sobre todo el último cuyo beneficio ponen un esmerado cuidado los interesados [...] Tiene además un numero de habitantes demasiado crecido, de sanas costumbres, vida sobria $y$ totalmente entregados a sus labores del campo [...] En cuanto al cultivo del café, esta industria está tomando un enorme incremento y no es aventurado conceptuar que en el curso de pocos años, este grano será uno de los elementos primordiales que habrán de alimentar el ferrocarril del Quindio, con efectivo provecho para el fisco nacional" (AGN, Tomo 669, F. 10).

\section{territarias 44}

se instalaron bodegas para almacenar café de las haciendas cercanas, embarcaderos y campamentos. Al estar ubicada en una cima de empinada pendiente sobre el acantilado del río Consota, su conexión precisó no solo de técnicas avanzadas para la construcción de un túnel que atravesara el montículo de Cerritos, sino de la implantación de acueductos y tanques para el abastecimiento de la locomotora, de gran recordación entre los habitantes del sector: "El tren paraba al frente del tanque para abastecer la locomotora con agua y mientras tanto le sacaban los vapores y el residuo de carbón de la caldera que lo tiraba a un lado de la carrilera" (Alirio Grajales, comunicación personal, 2017). ${ }^{17}$

De ahí, que durante el funcionamiento del tren ya existían pobladores que ocuparon los entornos de esa estación, que fue de gran atractivo tanto por su conexión con la red de acueducto como por ser fuente de trabajo ferroviario relacionado con el mantenimiento de la vía. Sin embargo, en las demás estaciones rurales solo se originaron asentamientos tras la desactivación del tren, lo que dio lugar a formas lineales de ocupación espontánea y crecimiento marginal, que se han extendido con el paso de los años.

\section{Ferrocarril del Quindío: de Nacederos $(\mathrm{km} \mathrm{0)}$ a Betulia $(\mathrm{km} \mathrm{18})$}

La línea del Quindío o NacederosArmenia, de propiedad nacional pero administrada por el Ferrocarril de Caldas, inició su construcción en 1925 partiendo del sector de Nacederos, donde se enlaza con una estación propia de conexión con la línea férrea caldense, para llegar hasta la ciudad de Armenia en 1927. Esta ferrovía recorre un paisaje de piedemonte con colinas y abanicos que conforman un sistema de lomeríos definidos por cuatro cuencas hidrográficas y sus redes de drenaje: río Consota, quebrada El Caucho, quebrada Cestillal y río Barbas. En este caso, su trazado no sigue los cursos hídricos, sino que los atraviesa de forma ondulante manteniéndose en altitudes de 1350 a 1400 msnm, condición óptima para el cultivo del café (figura 3). De esta manera, atravesó una zona rural de tradición cafetera, minifundista y densamente poblada, en un momento de inigualable crecimiento económico de la región y de la industria de exportación del grano. ${ }^{18}$

El trazado de $54 \mathrm{~km}$ fue diseñado por un grupo de ingenieros locales con experiencia previa en el Ferrocarril de Caldas, que proyectaron la ubicación de nueve estaciones o paraderos cada 5 o 6 $\mathrm{km}$ hasta la estación terminal de Armenia. De estas, hay cinco dentro del área del municipio de Pereira, distribuidas así: Estación Nacederos ( $\mathrm{km} \mathrm{0),} \mathrm{Estación}$ San Joaquín ( $\mathrm{km} \mathrm{6)}$, Paradero Morelia (km 11), Estación La Selva (km 14) y Paradero Betulia ( $\mathrm{km} \mathrm{18).} \mathrm{Su} \mathrm{construcción}$ fue dirigida por el ingeniero caucano Manuel María Mosquera, quien trabajó también en la línea férrea del Pacífico. De hecho, su arquitectura presenta más 
similitud en términos formales y constructivos con esta línea que con la de Caldas, pues se usan técnicas más modernas como la mampostería de ladrillo con machones de refuerzo en las aristas e intersecciones de los muros, el hormigón armado para estructuras de entrepiso y plataformas, y cerchas de madera y metal, lo que permite tener edificaciones de mayor área y altura. Por otra parte, los edificios férreos también tienen nuevas tipologías: plantas en forma de U con patio central (Nacederos y La Selva), patio posterior en forma de L (San Joaquín) o, en barra con un amplio hall transversal (Betulia y Morelia). Se destaca, además, su sistema de ventilación cruzada con ventanas superiores a lo largo de todas las fachadas.
Todo este trayecto de Nacederos a Betulia comprende espacios rurales de plantación y de beneficio húmedo del grano (SEl), donde además de la infraestructura férrea, es notoria la huella moderna dejada por la fuerte presencia institucional de la Federación Nacional de Cafeteros que, desde 1927 construye plantas de beneficiamento y secado de café, acueductos rurales, caminos y carreteras de conexión con las ferrovías -indicados con línea amarilla punteada en la planta de los conjuntos de la figura 9-. También en algunos casos, los propietarios de fincas y haciendas vecinas a los edificios férreos construyeron sus propias bodegas (Morelia). De modo que los cafeteros garantizaron el transporte de su café para ser

Figura 9. Trayecto Nacederos-Betulia
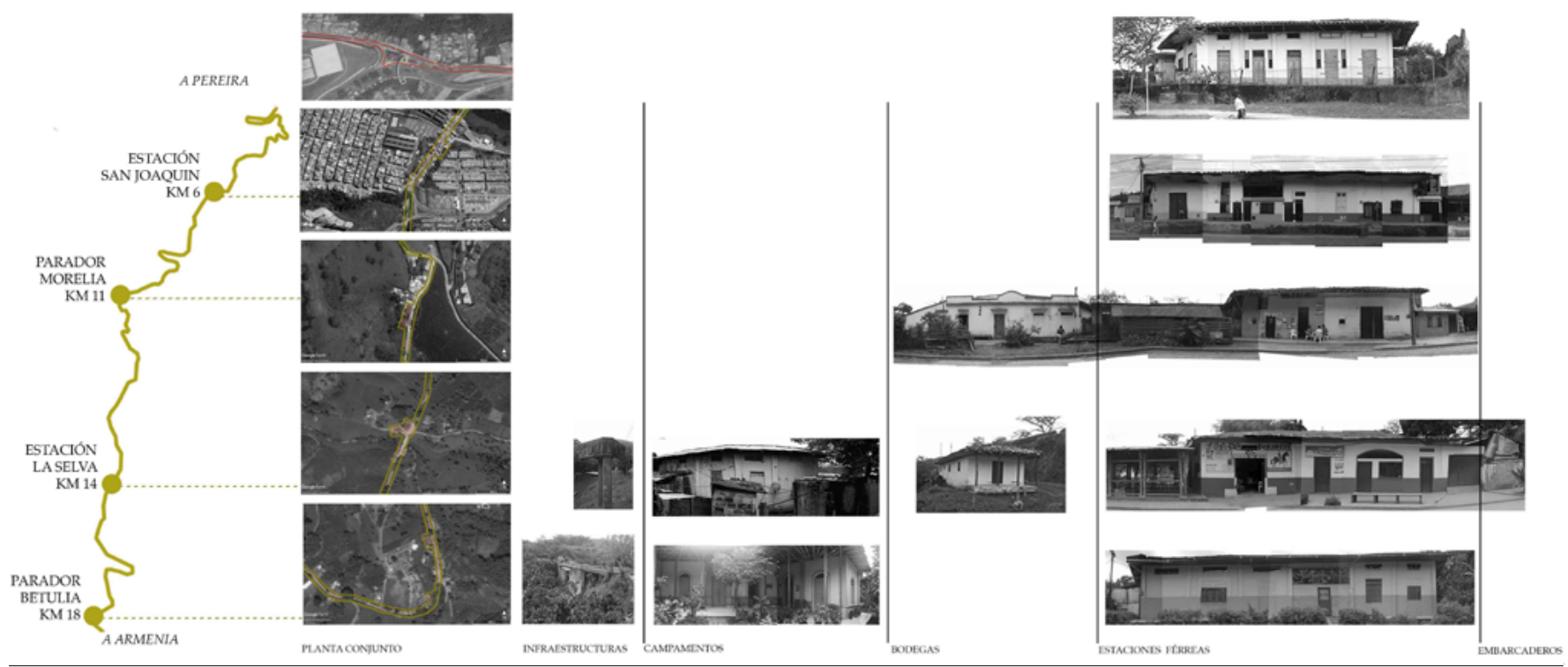

Fuente: elaboración propia (2019). 
trillado en Pereira. Al respecto comentan familiares de ferroviarios trabajadores de la línea, aún residentes en la zona:

Del Quindío para acá traían café, por aquí lo cosechaban y lo llevaban allá a las trilladoras al frente de la estación del ferrocarril. Por Morelia las fincas eran cafeteras, había plátano, yuca, no había tanta caña - como en la vía a Cartago - El café lo tenían en los beneficiaderos, todas las fincas tenían uno [...] ahí lo secaban [...] en las trilladoras era para escogerlo, era donde las muchachas trabajaban [...] llegaba negrito y había que pasarlo del otro [...] Las mujeres eran más ágiles para eso y también era más barato, pero les pagaban poco y trabajaban mucho (Carlos Vélez, comunicación personal, 2017).

Pero a pesar del impulso que la puesta en funcionamiento de la línea le dio a la economía cafetera local, rápidamente las fluctuaciones en los ingresos generadas por la concentración en las dos cosechas anuales y la inestabilidad en los meses restantes, desequilibró la situación económica de la empresa. Este escenario se agravaría con la apertura de la carretera Pereira-Armenia y del ramal ferroviario Zarzal-Armenia, así pues, a partir de la década de 1930, la línea pasó a ser administrada por el Ferrocarril del Pacífico y, en 1969 comenzaría su desactivación con la aprobación del levantamiento de rieles. Ya para 1972 los trenes llegaban solo hasta San Joaquín, y pocos años después, se canceló totalmente el servicio.
Más adelante, la ocupación de los entornos ferroviarios de las estaciones $\mathrm{Na}$ cederos y San Joaquín, dieron origen a dos nuevos núcleos urbanos de expansión: el barrio Nacederos, en la carretera a Cartago junto al aeropuerto y, el populoso barrio Cuba en el suroccidente. En cambio, las demás estaciones se encuentran aún en un área rural de tradición cafetera, donde prevalece el minifundio como sistema de propiedad con cultivos de pancoger, concentración de población campesina y una fuerte presencia de la unidad familiar productora en casas de arquitectura vernácula. Debido a ello, esta zona constituye hoy en día una de las áreas protegidas por la declaratoria Unesco del Paisaje Cultural Cafetero. A pesar de esto, hay un creciente fenómeno de expansión urbana, suburbanización y rururbanización que amenaza su conservación.

\section{Ferrocarril del Pacífico: km 367-Estación Caimalito-km 374}

La conexión de las líneas de Caldas y del Pacífico constituyó un nodo estratégico del ambicioso proyecto "Troncal de Occidente", creado durante el Gobierno de Marco Fidel Suárez (1919-1922), para unir el Ferrocarril del Pacífico a través del valle del río Cauca, con el Ferrocarril de Antioquia y el de Bolívar hasta llegar a Cartagena en el mar Caribe. Tras muchos intentos fallidos, se logró finalmente que en 1931 el Ferrocarril del Pacífico llegará a Pereira, gracias a la construcción de un 
puente metálico de gran luz $(70 \mathrm{~m})$ que atravesó el río Cauca entre Cartago y La Marina. A partir de allí, la línea férrea atravesaría Puerto Caldas y, siguiendo el curso del río Cauca hasta la altura del puerto de La Virginia, llegaría hasta Caimalito en el $\mathrm{km} 370$. Esto implicaría la transformación de Puerto Caldas de estación terminal a estación de paso y el traslado de sus funciones hacia la nueva estación.

Por consiguiente, en medio del tramo de 7 km que la Línea Férrea del Pacífico tenía en el municipio de Pereira, entre Puerto Caldas (km 367) y la desembocadura del río Otún ( $\mathrm{km} 374)$, se construyó un conjunto férreo de gran escala, que aglomeraba los antiguos espacios portuarios de comercialización y exportación (SE4) y, se consolidó como una estación central de puerto seco.
En consecuencia, en Caimalito se construyó el complejo férreo de mayor envergadura de la ciudad, compuesto de estación, bodegas, embarcadero, casa de ingenieros-jefe de estación y siete campamentos de trabajadores férreos, además de variadas obras de arte (figura 10). Aquí, el ingeniero Mosquera, que recién había edificado las estaciones del Ferrocarril del Quindío, construyó una arquitectura ferroviaria con características formales y constructivas similares a las de la línea anterior, de transición entre la arquitectura de la colonización antioqueña y el estilo republicano. A excepción de la casa de ingenieros, construida en madera, los edificios tienen un sistema constructivo de muros portantes en mampostería de ladrillo macizo de arcilla a la vista, en los que se destacan los zócalos revestidos y

Figura 10. Trayecto Ferrocarril Pacífico-Caimalito

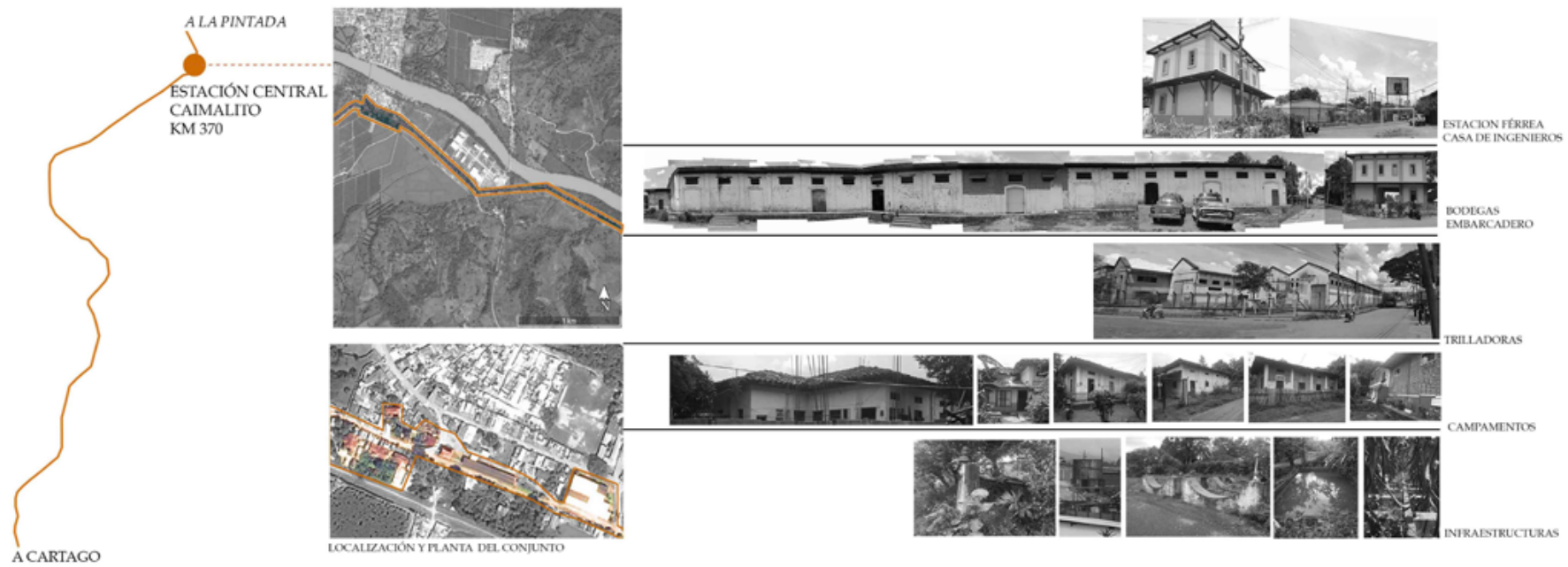

Fuente: elaboración propia (2019). 
${ }^{19}$ Juan Bautista Restrepo. Actual corregidor de Caimalito y extrabajador de Almacafé.

territarias 44 los elementos estructurales con modestas molduras y cornisas. Cabe anotar que la Estación Caimalito es el único edificio férreo de dos pisos en el área rural, con una tipología en la que se destaca el vacío central en el primer piso, que configura un corredor público cubierto.

Si bien este complejo múltiple contó con gran dinámica desde sus inicios, su consolidación como centro de almacenamiento y distribución cafetera, se dio solo una vez que se trasladaron desde el centro de la ciudad las trilladoras y depósitos industriales de Almacafé. A partir de entonces se almacenaba ahí la producción de las montañas risaraldenses que era trasladada en tren hacia el puerto de Buenaventura, permitiendo que la producción cafetera del occidente del país se triplicara (Poveda, 2003). Como cuentan los braceros habitantes del sector:

A Almacafé llegaban con el café de todos los municipios aledaños: Belalcázar, La Virginia, Viterbo, Belén de Umbría, La Celia, Apia, Santuario. En la estación grande se almacenaba y era cargado por cuadrilleros que eran pagados por Almacafé. La carga era aproximadamente dos veces por semana y se pagaba por tonelada (J. B. Restrepo, comunicación personal, 2017). ${ }^{19}$

Tras la suspensión del servicio férreo en 1972, las trilladoras siguieron en funcionamiento hasta la década de 1990, conectadas por carreteras con los demás centros comercializadores y puertos. Sin embargo, al atraer gran cantidad de mano de obra, los entornos férreos fueron ocupados informalmente, a tal punto que, hoy en día Caimalito constituye el centro poblado más denso y pobre del área rural de Pereira. Aunque a pesar de las transformaciones funcionales que ha sufrido, por su localización y articulación vial hay gran interés de consolidarlo como una zona franca internacional en la actualidad. En esa dirección, se lleva a cabo la rehabilitación del tramo ferroviario Zarzal-Cartago-La Felisa y se proyecta la reutilización de las antiguas líneas férreas como una red de ciclovías regional (Región Administrativa de Planificación Eje Cafetero, 2018).

\section{Conclusiones y consideraciones finales}

La lectura histórica y multiescalar de la construcción del territorio cafetero realizada, constituye una visión sistémica del paisaje cafetero a través del estudio de su patrimonio ferroviario e industrial. A través de ella, es posible comprobar, en primer lugar, que los trazados férreos y el esquema de estaciones múltiples de Pereira, puestos sobre un soporte físico de grandes variaciones entre valle y montaña y, en estructuras de propiedad disímiles, fueron el resultado de intereses de propietarios de tierra locales, de medios de producción regionales, nacionales y extranjeros que buscaron minimizar costos de transporte y maximizar la capacidad 
productiva. Para ellos, el Estado invirtió en el tendido de redes técnicas - ferrovías, carreteras, electricidad, telefonía, acueductos-, construcción de conjuntos férreos rurales y distritos industriales urbanos, donde se crearon economías de aglomeración. Entonces, articulando todos los sistemas espaciales de la cadena productiva cafetera, de la producción a la exportación, y conectándose con los principales centros de comercialización y exportación, el tren posibilitó que la ciudad se posicionara como una de las principales plazas productoras y comercializadoras de café en la región y en el país, pasando de ser un municipio tributario de Manizales a ser su mayor competidor, y por tanto, ejerciendo presión por un espacio representativo en el Viejo Caldas.

A su paso por el espacio rural y urbano de Pereira, el tren transformó y modernizó el paisaje, rompiendo lentamente con las tradiciones urbanísticas y arquitectónicas heredadas de la colonización antioqueña $y$, configurando nuevas centralidades que incidieron directamente en la orientación de la expansión de la ciudad, en la definición de sus límites y formas de crecimiento. En el área urbana, el trazado férreo del Ferrocarril de Caldas reconfigura el límite urbano-rural y define el borde sur de la ciudad, dando origen a un enclave industrial donde se concentran usos y agentes sociales en conflicto: el conjunto férreo, las trilladoras de café y los barrios obreros. Así, se creó un efecto barrera en donde, de un lado de la ferrovía, la élite construye un espacio moderno de encuentro cívico, producción, trabajo industrial, y, del otro, los grupos excluidos consolidan su espacio de habitación, muchas veces al margen de las políticas de vivienda higienistas de la época.

En el área rural, cada línea férrea definió nuevas configuraciones territoriales de acuerdo con su soporte geográfico, a las funciones determinadas por la dinámica interna del ferrocarril y a su papel dentro de la cadena productiva cafetera. En primer lugar, a lo largo del Ferrocarril del Quindío, donde se concentran hasta hoy día los espacios rurales de plantación en lomerío y de beneficio húmedo (SEl) del grano, hay una continuidad de las condiciones de tenencia y uso de la tierra que existían incluso antes de la llegada del ferrocarril y que inhiben su urbanización. En cambio, en el Ferrocarril de Caldas y del Pacífico, los espacios de beneficio seco, trilla y selección del grano (SE2) del área urbana, los espacios intermedios de almacenamiento (SE3) en el piedemonte y el puerto de comercialización y exportación (SE4) en la zona de Valle, atrajeron a gran cantidad de mano de obra y potenciaron la urbanización.

En suma, se hace evidente que el patrimonio férreo e industrial cafetero de Pereira, además de responder a una función determinada por la dinámica interna del ferrocarril, soporta las actividades productivas externas, adaptando su configuración formal y usos a las dinámicas territoriales. Sus elementos asumen 
características particulares del sistema de producción cafetero local: los paraderos garantizan la carga en áreas aisladas y el transporte de pasajeros en las zonas de mayor movilidad y concentración de población rural, mientras que las estaciones se trasforman en estaciones-bodega, y conforman conjuntos industriales cafeteros o complejos múltiples, de acuerdo con su papel y ubicación en la cadena productiva. Así, del campo a la ciudad, el paso del tren y la evolución de las técnicas de beneficio, modernizan el paisaje cafetero dejando profundas marcas en el paisaje.

Teniendo en cuenta dichos hallazgos, se considera que este trabajo constituye una contribución tanto a nivel conceptual, con la definición del Conjunto Industrial Cafetero urbano, como a nivel metodológico para el estudio de la transformación del paisaje cafetero. En esa medida, invita a construir nuevas miradas sobre la conservación, integridad y sostenibilidad de los paisajes agrarios e industriales. $\mathrm{Y}$ es que frente al preocupante proceso de deterioro, desaparición y pérdida de apropiación social que está sufriendo este patrimonio férreo e industrial cafetero, al que los instrumentos de preservación del patrimonio responden insuficientemente, es preciso hacer un llamado a pensar cómo la delimitación territorial de los paisajes y de lecturas morfológicas, redundan en posibilidades de gestión y preservación diferenciadas. En este sentido, se abre el camino para reflexionar si las redes viales que soportan el proceso productivo, al definir un sistema estructurante del territorio, pueden valorarse no solo $\mathrm{co}^{-}$ mo objeto de preservación, sino como base para la creación de instrumentos de planeamiento, preservación y gestión del paisaje, en el marco de la ordenación territorial como proceso institucional de carácter vinculante.

\section{Referencias}

Ángel, H. (1983). Pereira: proceso histórico de un grupo étnico colombiano. Gráficas Olímpica.

Aprile, J. (1992). La Ciudad Colombiana: siglo XIX y siglo XX. Talleres Gráficos Banco Popular.

Arango, M. (1981). Café e industria (18501930). Cie Universidad de Antioquia; Carlos Valencia Editores.

Archivo General de la Nación (AGN). Fondo Ferrocarriles Nacionales-Linea Nacederos-Armenia [Tomo 669, Folio 10]. Archivo General de la Nación.

Archivo General de la Nación (AGN). Fondo Ferrocarriles Nacionales-Empresa Caldas [Tomo 323, folio 66, 111, 156, 240, 275, 276]. Archivo General de la Nación.

Argollo, A. (2015). Arquitetura do café. Unicamp.

Bellet, C., \& Llop, J. (2004). Miradas a otros espacios urbanos: las ciudades intermedias. Geo Critica Scripta Nova: Revista Electrónica de Geografía $y$ Ciencias Sociales, 8(165), 741-798.

\section{territarias 44}


http://www.ub.edu/geocrit/sn/sn165.htm

Café exportado desde Pereira 1939. (1940). Revista Cafetera de Colombia, 7(105).

Camacho, A. (2013). Fotografías antiguas de Pereira [Fotografías]. Archivo fotográfico personal. Pereira.

Cámara de Comercio de Pereira. (2013). Registros comerciales trilladoras 19101970. Archivo Cámara de Comercio de Pereira, ACCP.

Capel, H. (2011). Redes técnicas y ferrocarriles en la ciudad. Fundación de los Ferrocarriles españoles.

Ceballos, O. L. (2008). Vivienda social en Colombia: una mirada hacia su legislación. Editorial Pontificia Universidad Javeriana.

Ciudades y Gobiernos Locales Unidos, CGLU. (2018, 7 de julio). Carta-Declaración de Chefchaouen de las Ciudades Intermedias del mundo. Primer Foro Mundial de Ciudades Intermedias. Chefchaouen, Marruecos.

Concejo Municipal de Pereira. (1920, 29 de octubre). Artículo 1. Acuerdo $n .^{\circ}$ 21, por medio del cual se declara el área urbana o trazado de la ciudad y sus linderos. Documento impreso del Archivo del Concejo Municipal de Pereira.

Concejo Municipal de Pereira. (1924, 25 de enero). Artículo 1. Acuerdo $n .^{\circ} 4$, por medio del cual se dictan algunas disposiciones de conveniencia pública. Documento impreso del Archivo del Concejo Municipal de Pereira.
Concejo Municipal de Pereira. (1926, 30 de abril). Artículo 1. Acuerdo $n .^{\circ} 33$, por medio del cual se dictan algunas disposiciones de conveniencia pública. Documento impreso del Archivo del Concejo Municipal de Pereira.

Concejo Municipal de Pereira. (1942, 6 de febrero). Artículo 1. Acuerdo n. ${ }^{\circ}$, por medio del cual se aprueba un contrato sobre urbanización. Documento impreso del Archivo del Concejo Municipal de Pereira.

Departamento Administrativo Nacional de Estadística (DANE). (1951). Censo de Población. Multilith-Estadinal. http:// biblioteca.dane.gov.co/media/libros/ LB_896_1951.PDF

Departamento Administrativo Nacional de Estadística (DANE). (1964). XIII Censo Nacional de Población. Imprenta Nacional. http://biblioteca.dane.gov. co/media/libros/LD_771_1964.PDF Duque, L., Friede, J., \& Jaramillo, J. (1963). Historia de Pereira. Edición Club Rotario de Pereira.

Escobar, C. (1995). Las escogedoras de café en el Antiguo Caldas (1930-1940). Universidad Tecnológica de Pereira.

García, A. (1978). Geografía económica de Caldas. Banco de la República.

Instituto Geográfico Agustín Codazzi, IGAC. (1954). Aerofotografía de Pereira. https://geoportal.igac.gov.co/

Kuhl, B. M. (1998). Arquitetura do ferro e arquitetura ferroviária em São Paulo: reflexões sobre a sua preservação. Ateliê Editorial. 
Kuhl, B. M. (2010). Patrimônio industrial: algumas questões em aberto. USJT: Arqurb, (3), 23-30. https://revistaarqurb. com.br/arqurb/article/view/115

Lalana Soto, J. L., \& Santos y Ganges, L. (2013, 12 al 15 de junio). Retos metodológicos en el estudio, evaluación y tratamiento del patrimonio ferroviario. En El patrimonio industrial en el contexto histórico del Franquismo 1939-1975: territorios, arquitecturas, obras públicas, empresas, sindicatos y vida obrera. Anales VI Congreso para la conservación del patrimonio industrial $y$ de la obra pública en España (pp. 125-132). TiCCIH-España.

Latorre, E. (1986). Transporte y crecimiento regional en Colombia. UniAndes; Fondo Editorial CEREC.

Lobato, R. (1989). O Espaço Urbano. Editora Ática.

McGreevey, W. P. (1988). Historia económica de Colombia 1845-1930. Tercer Mundo Editores.

Medina, C. (1971). Conjunto Industrial Cafetero desde Edificio Invico en construcción [Fotografía]. Archivo fotográfico Gabriel Jaime Cano. Pereira.

Microfilmado Biblioteca Nacional. (1919). Revista el gráfico, 51(508), 119.

Ministerio de Cultura de Colombia. (2011). Paisaje Cultural Cafetero: un paisaje cultural productivo en permanente desarrollo. Ministerio de Cultura de Colombia República de Colombia.

Ministerio de Cultura de Colombia. (2020). Bienes de Interés Cultural del ámbito nacional. Ministerio de Cultura de Colombia, República de Colombia. https://www.mincultura.gov. co/areas/patrimonio/patrimonio-cultural-en-Colombia / bienes-de-interes-cultural-BICNAL/ Paginas/default.aspx

Muriel, R. D. (1999). Colombia: comercio $y$ transportes 1850-1929. Editorial Pi.

Palacios, M. (1983). El café en Colombia 1850-1970: una historia económica, social y politica. El Ancora.

Pérez, E. (1998). Ferrocarriles, desarrollo regional y urbano en Colombia. Bitácora Urbano Territorial, 1(2), 8-19. https://tinyurl.com/y6d6odk6

Posada, J. (1918). Libro Azul de Colombia. The J. J. Little \& Ives Comp.

Poveda, G. (2003). El antiguo ferrocarril de Caldas. Revista DrNA, 70(139), 1-10. https://www.redalyc.org/ pdf/496/49613902.pdf

Ramírez, A. (2016). El Ferrocarril de Caldas. Hoyos Editores.

Ramírez, R. (2010). Clase obrera urbana en la industria del café. Escogedoras, trilladoras y régimen laboral en Antioquia, 1910-1942. Revista Desarrollo y Sociedad, (66), 115-143. https://doi. org/10.13043/dys.66.4

Región Administrativa de Planificación Eje Cafetero. (2018). Documento técnico de soporte. Gobierno de Caldas.

Rivera, J. A., Sánchez, L. F., \& Cristancho, H. (2019). El centro del eje. Fascículo Eje Cafetero. Revista Semana, a historia contada desde las regiones, 
pp. 292-295. http://semanahistoria. com/fasciculos/eje-cafetero/

Rivera, T. (2015). El Conjunto Industrial Cafetero: actores y agentes urbanos en la construcción de la Pereira moderna. (Tesis de Maestría). Facultad de Arquitectura y Urbanismo. Universidad Federal de Río de Janeiro.

Sabaté, J., \& Galindo, J. (2009). El valor estructurante del patrimonio en la transformación del territorio. Revista Apuntes, 22(1), 20-33. https:// revistas.javeriana.edu.co/index.php/ revApuntesArq/article/view/8945

Santos, M. (1996). A natureza do espaço. Hicitec.

Santos, M. (2004). Por uma geografia nova (6 Ed.). Edusp.

Silva, J. M. P., Manetti, C., \& Tângari, V. (2013). Compartimentos e unidades de paisagem: método de leitura da paisagem aplicado à linha férrea. Paisagem e Ambiente, (31), 61-80. https:// doi.org/10.11606/issn.2359-5361. v0i3lp61-80

Sobrino Simal, J., \& Sanz Carlos, M. (Eds.). (2019). Carta de Sevilla de Patrimonio Industrial 2018. Los retos del siglo XXI.
Fundación Pública Andaluza Centro de Estudios Andaluces; Consejería de la Presidencia, Administración Pública e Interior; Junta de Andalucía.

Tagil, N. (2003). Carta de Nizhny Tagil sobre patrimonio. International Committee for the Conservation of the Industrial Heritage, TICCIH; Unesco. https:// www.icomos.org/18thapril/2006/ nizhny-tagil-charter-sp.pdf

Therrien, M. (2008). Patrimonio y arqueología industrial: ¿̇nvestigación vs. protección? Políticas del patrimonio industrial en Colombia. Revista de Estudios sobre Patromonio Cultural, 21(1), 44-61.

Unesco. (2011). Nominations of properties to the World Heritage List. World Heritage Comittee Thirty-fifth session. Paris. https://whc.unesco.org/archive/2011/whcll-35com-20e.pdf

Zambrano, F., \& Bernard, O. (1998). Ciudad y territorio: el proceso de poblamiento en Colombia. Instituto Francés de Estudios Andinos.

Zuluaga, V. (2004). La nueva historia de Pereira: Fundación. Universidad Tecnológica de Pereira. 